\title{
Renal transplantation increases angiotensin II receptor-mediated vascular contractility associated with changes of epigenetic mechanisms
}

\author{
YAKUN ZHAO $^{1 *}$, QINGGUO ZHU ${ }^{1 *}$, SHIPING SUN $^{1}, \mathrm{YU} \mathrm{QIU}^{1}, \mathrm{JINGQUAN} \mathrm{LI}^{1}$, \\ WEI LIU ${ }^{1}$, GANGJUN YUAN ${ }^{1}$ and HUA MA ${ }^{2}$ \\ ${ }^{1}$ Department of Urinary Surgery, The Second Affiliated Hospital of Harbin Medical University, Harbin, Heilongjiang 150086; \\ ${ }^{2}$ Surgical Department, The People's Hospital of Fuyun County, Aletai, Xinjiang 836100, P.R. China
}

Received August 10, 2016; Accepted December 21, 2017

DOI: 10.3892/ijmm.2018.3435

\begin{abstract}
Hypertension is one of the most common complications following renal transplantation, and it increases the risk of graft loss and other cardiovascular diseases. Previous studies have revealed that the use of angiotensin II (Ang II) blockers for preventing and treating hypertension is closely associated with higher survival following renal transplantation. However, the cellular and molecular mechanisms by which the vascular contractility of the recipient is altered in response to Ang II following renal transplantation have not been fully elucidated. In the present study, using the Fisher-Lewis rat kidney transplantation model, the blood pressure (BP) of the conscious transplant recipient was measured following the intravenous administration of Ang II. In addition, the mechanisms underlying the Ang II-mediated vascular contractility via the type 1 and type 2 Ang II receptors $\left(\mathrm{AT}_{1} \mathrm{R}\right.$ and $\mathrm{AT}_{2} \mathrm{R}$, respectively) in large and small-resistance blood vessels were determined in the recipient after renal transplantation. The results showed that renal transplantation significantly increased the Ang II-stimulated BP of the rats. Additionally, ex vivo contractility experiments using aorta and mesenteric arteries revealed that the contractions induced by Ang II were significantly strengthened in the recipient following renal transplantation, and were associated with an increased intracellular $\mathrm{Ca}^{2+}$ concentration. Losartan almost eradicated the Ang II-induced contractions whereas PD-123319 had no apparent effects on the Ang II-induced contractions in the aorta and mesenteric arteries of the recipient. Furthermore, the expression levels of $\mathrm{AT}_{1} \mathrm{R}$ but not $\mathrm{AT}_{2} \mathrm{R}$ were significantly
\end{abstract}

Correspondence to: Dr Qingguo Zhu, Department of Urinary Surgery, The Second Affiliated Hospital of Harbin Medical University, 148 Baojian Road, Harbin, Heilongjiang 150086, P.R. China E-mail: qingguo_zhu@126.com

*Contributed equally

Key words: renal transplantation, vascular contractility, angiotensin II, epigenetics increased in the vasculature of the recipient following renal transplantation, which exhibited a close association with selective DNA demethylation detected in the promoter region of the vascular $\mathrm{AT}_{1 \mathrm{a}} \mathrm{R}$ gene. These results indicate that changes of recipient vascular $\mathrm{AT}_{1} \mathrm{R}$ gene expression, occurring through a mechanism involving DNA methylation, increase the vascular contractility in response to Ang II. This may lead to the increased risk of hypertension following renal transplantation.

\section{Introduction}

Renal transplantation has distinct advantages over other medical interventions for end-stage kidney diseases in improving survival and the quality of life (1). Owing to the development of effective antimicrobial prophylactics for periand post-operative care, the early diagnosis of post-operative complications, and potent immunosuppressants for reducing acute rejection, short-term transplant results are now excellent with a steady increase in patient and graft survival (2). However, due to patients with a functioning graft succumbing due to a range of etiologies, including cardiovascular diseases and malignancies, the long-term outcomes of renal transplantation remain a critical concern $(3,4)$. Notably, hypertension is one of the most common and serious complications following renal transplantation, and is an important risk factor for graft loss and other disorders $(5,6)$. In particular, increased stiffness and altered contractility of blood vessels are observed following renal transplantation, and may contribute to the pathogenesis of abnormal blood pressure (BP) $(7,8)$. It is generally considered that the renin-angiotensin system (RAS) serves systemic endocrine or local paracrine/autocrine functions, eliciting either beneficial or detrimental effects on cardiovascular homeostasis $(9,10)$. Angiotensin II (Ang II), as the essential bioactive peptide of the RAS, exerts crucial roles in the regulation of the cardiovascular system, particularly BP, and in the pathogenesis of cardiovascular diseases such as hypertension (11). The majority of the physiological and pathological roles of Ang II in the control of vascular contractility are largely mediated via its interaction with two G-protein coupled receptors known as the type 1 and type 2 Ang II receptors $\left(\mathrm{AT}_{1} \mathrm{R}\right.$ and $\mathrm{AT}_{2} \mathrm{R}$, respectively) (12). In physiological conditions, Ang II mainly 
binds to $\mathrm{AT}_{1} \mathrm{R}$ to activate the contraction of smooth muscle cells and maintain the vascular tone (13). In the pathogenesis of cardiovascular diseases such as hypertension, Ang II binds to $\mathrm{AT}_{1} \mathrm{R}$ and $\mathrm{AT}_{2} \mathrm{R}$ in smooth muscle cells and endothelial cells, which increases the contractility and phenotype/morphology of the vasculature and eventually leads to BP elevation (14). A previous study revealed that the contractility of blood vessels in response to Ang II was markedly increased in the recipient following renal transplantation (15). Notably, clinical research has demonstrated that therapies using Ang II blockers for the prevention and treatment of hypertension are closely associated with higher survival following renal transplantation $(16,17)$. However, whether and to what extent the cellular and molecular mechanisms underlying Ang II-induced vascular contractility are changed following renal transplantation have not yet been fully elucidated.

Notably, emerging studies have revealed that epigenetic mechanisms, which are biological processes that cause heritable changes in gene expression without altering the DNA sequence, exert essential effects on the clinical outcomes following renal transplantation (18). These epigenetic changes include non-coding RNA, DNA methylation and post-translational histone modifications (19). Typical epigenetic alterations in the pathogenesis of certain disorders following renal transplantation have been investigated (20). It has been suggested that the epigenome of the donor may influence kidney graft survival, particularly when the epigenetic modifications are associated with early stresses and donor aging (21). In clinical applications, certain epigenetic modifications associated with the processes of ischemia-reperfusion injury, host immune responses to graft and graft responses to injury have been tentatively suggested to serve as potential tools for evaluating graft function, and as new therapeutic targets for improving outcomes following renal transplantation (22-24). However, whether the altered Ang II-induced vascular contractility following renal transplantation is associated with epigenetic changes of the $\mathrm{AT}_{1} \mathrm{R}$ and $\mathrm{AT}_{2} \mathrm{R}$ genes is unclear.

In humans, factors including uremia, pre-existing vascular diseases, volume load, abnormal calcium phosphate metabolism, and the limitations of examination methods interfere with the study of the explicit effects of renal transplantation on recipient cardiovascular functions (25). However, experimental animal models may effectively exclude the aforementioned obstacles (26). Thus, in the present study, an experimental Fisher-Lewis rat renal transplantation model was used. The changes of $\mathrm{BP}$ in the conscious state and the vascular contractility of large and small blood vessels in response to Ang II of the recipient animal following renal transplantation were investigated. Additionally, the mechanism by which Ang II modulates vascular contractility via the activation of $\mathrm{AT}_{1} \mathrm{R}$ and $\mathrm{AT}_{2} \mathrm{R}$ in the recipient was determined following renal transplantation. Furthermore, alterations in the patterns of DNA methylation were investigated, so as to elucidate the effects of renal transplantation on the epigenetic modifications affecting gene expression at the transcriptional level. Accordingly, the cellular and molecular impacts of renal transplantation on Ang II-induced vasoconstriction in the transplant recipient were extensively explored, and the results may provide potential candidates that may be targeted to prevent and ameliorate hypertension following transplantation.

\section{Materials and methods}

Experimental animals and treatment. Male Fisher rats $(\mathrm{n}=12)$ and Lewis rats $(n=12)$ weighing 250-300 $\mathrm{g}$ were supplied by the Laboratory Animal Research Center of Harbin Medical University (Harbin, China). The rats were individually housed in plastic cages in an animal room under temperature-controlled conditions of $22-25^{\circ} \mathrm{C}$ and humidity of $50-60 \%$ with a $12-\mathrm{h}$ light/dark cycle and access to commercial pellets and water ad libitum. The rats were maintained under these standard conditions for $\geq 1$ week prior to experimentation. The rats were randomly assigned into groups ( $\mathrm{n}=12$ for each group), and the following experiments and drug treatments were performed in a double-blind manner. The control group (Con) was subjected to a sham surgery. The renal transplantation (RT) group received the typical Fisher-Lewis rat renal transplantation surgery. Both surgeries are described in detail below. In the first 10 days following the renal transplantation surgery, all experimental rats were treated with cyclosporine by intraperitoneal injection $(1.5 \mathrm{mg} / \mathrm{kg} /$ body weight $)$ once every day. All procedures were approved by Harbin Medical University Animal Ethics Committee and conformed to the Guide for the Care and Use of Laboratory Animals (5th Edition, 2015).

Renal transplantation procedure. Following anesthesia with an intraperitoneal injection of $3 \%$ sodium pentobarbital (50 mg/kg) under sterile conditions, the kidneys and vessels of the rats were exposed through an abdominal midline incision. Microsurgery was performed simultaneously in the donor (Fisher) and recipient (Lewis) rats by two investigators. In the two rats, blood flow through the small branches of the abdominal aorta and vena cava was arrested by ligation using vessel clips. The left kidney of the donor rat, including the ureter, the renal artery and a short section of the aorta and the renal vein, was perfused with ice-cold electrolyte solution and immediately transferred to the recipient rat. The aorta and renal vein of the donor kidney, which was kept in gauze and superfused with ice cold electrolyte solution, were sutured to the aorta and vena cava end-to-side of the recipient rat. Following ligation of the distal end of the graft aorta, the vessel clips in the recipient rat were released. During this process, the graft experienced $\leq 40 \mathrm{~min}$ ischemia in total. The ureter of the donor kidney was inserted into the apex of the recipient bladder. Finally, following flushing of the abdominal cavity with isotonic saline, the abdomen was closed in layers. The right native kidney of the recipient rat was removed 10 days after the left kidney transplantation surgery. In the sham surgery, following an abdominal midline incision, the kidneys and vessels were exposed by pulling the mesentery out of the abdomen. All visible renal nerves were cut for renal denervation, and the renal artery and vein were dissected free from connective tissue and clamped for $40 \mathrm{~min}$ for warm ischemia. The mesentery was then put back into the abdominal cavity, and the abdomen was closed in layers.

Determination of blood biochemical indices. At 48 weeks after the transplantation surgery, the rats were anesthetized with $3 \%$ sodium pentobarbital $(50 \mathrm{mg} / \mathrm{kg})$ intraperitoneally and 2-ml blood samples were collected via the abdominal aorta into iced tubes containing lithium heparin (Sigma-Aldrich; Merck 
KGaA,Darmstadt, Germany) as an anticoagulant. Arterialblood $\mathrm{pH}$, plus the hematocrit (Hct), glucose (Glu) and lactate (Lac) concentrations, the sodium concentration $\left(\left[\mathrm{Na}^{+}\right]\right)$and potassium concentration $\left(\left[\mathrm{K}^{+}\right]\right)$of the blood were evaluated using a Nova eleven-electrode analyzer (Nova Biomedical, Waltham, MA, USA). The samples were centrifuged at $2,000 \times \mathrm{g}$ at $4^{\circ} \mathrm{C}$ for $10 \mathrm{~min}$ to remove erythrocytes, leukocytes and platelets. The plasma was then extracted and its osmolality measured using an advanced diagnostic osmometer (Model MO; Advanced Instruments, Inc., Norwood, MA, USA).

Measurement of Ang II levels in plasma and blood vessels. Blood samples were collected from the rats as described above, with the exception that the collection tubes were iced tubes containing ethylenediaminetetraacetic acid (EDTA) as the anticoagulant. The plasma was extracted by centrifugation at $2,000 \times \mathrm{g}$ at $4^{\circ} \mathrm{C}$ for $10 \mathrm{~min}$, and then aliquoted and frozen at $-80^{\circ} \mathrm{C}$ until required for testing. In addition, the aorta and mesenteric arteries were excised and placed in chilled plastic tubes containing EDTA-Na ${ }_{2}, 8$-hydroxyquinoline and dimercaptopropanol. The tissue samples were boiled in water at $100^{\circ} \mathrm{C}$ for $10 \mathrm{~min}$ to provide a blood vessel tissue homogenate, which was then centrifuged at 2,200 $\mathrm{x} g$ at room temperature for $10 \mathrm{~min}$. The supernatant was aliquoted and frozen at $-80^{\circ} \mathrm{C}$ until required. The levels of Ang II in the plasma and blood vessels were detected by routine radioimmunoassay, using commercially available kits (cat. no. HY-10058; Beijing Sino-UK Institute of Biological Technology, Beijing, China) with a sensitivity of $0.01 \mathrm{ng} / \mathrm{ml}$, and intra- and inter-assay coefficients of variation of $10.5-12.0 \%$. Vascular contractility of the aortas in the absence of endothelium was examined by allowing air bubbles blew into the vascular lumen at 10 -sec intervals for a total duration of $5 \mathrm{~min}$.

Arterial BP measurements in conscious rats. At 48 weeks after the transplantation surgery, the rats were intraperitoneally anesthetized with $3 \%$ sodium pentobarbital $(50 \mathrm{mg} / \mathrm{kg})$, and polyvinyl catheters were introduced into the femoral artery and femoral vein under sterile conditions for arterial BP recording and drug administration, respectively. Following the surgery, antibiotics were administered subcutaneously for 2 days. On the third day, the arterial BP of the conscious rats was measured continuously. Following the recording of baseline measurements for $60 \mathrm{~min}$, Ang II (100 ng/kg body weight; Sigma-Aldrich; Merck KGaA) was intravenously administered via the implanted catheter in the femoral vein. The basal arterial BP was then continuously recorded for 60 min. A selective $\mathrm{AT}_{1} \mathrm{R}$ antagonist (losartan; $1 \mathrm{mg} / \mathrm{kg}$, in $0.2 \mathrm{ml}$ saline) and $\mathrm{AT}_{2} \mathrm{R}$ antagonist (PD-123319;0.1 mg/kg, in $0.2 \mathrm{ml}$ saline) (both Sigma-Aldrich; Merck KGaA) were respectively administered intravenously via the implanted catheter. The resting arterial BP was then continuously recorded for $60 \mathrm{~min}$. Continuous recording and data acquisition of the arterial systolic BP (SBP), diastolic BP (DBP) and mean BP (MAP) was conducted using a PowerLab system and software (LabChart software version 6; ADInstruments, Bella Vista, Australia).

Aortic ring contractility. At 48 weeks after the transplantation surgery, the rats were intraperitoneally injected with
$3 \%$ sodium pentobarbital $(50 \mathrm{mg} / \mathrm{kg})$. The thoracic aorta was then isolated and cut into 4-mm rings, which were mounted in tissue baths $(10 \mathrm{ml})$ containing modified Krebs solution equilibrated with $95 \% \mathrm{O}_{2}$ and $5 \% \mathrm{CO}_{2}$ at $37^{\circ} \mathrm{C}$. Following a $60-\mathrm{min}$ equilibration period, the rings were stretched to an optimal resting tension and then stimulated with increasing concentrations of Ang II $\left(10^{-11}-10^{-5} \mathrm{~mol} / \mathrm{l}\right)$ in one-half log increments. In addition, losartan $(10 \mu \mathrm{mol} / \mathrm{l})$ or PD-123319 $(10 \mu \mathrm{mol} / \mathrm{l})$ were used to pretreat the rings for $30 \mathrm{~min}$ prior to the addition of Ang II. The contractile tension was continuously recorded, with normalization by the maximum contraction elicited by $60 \mathrm{mmol} / 1 \mathrm{KCl}$. As the repeated exposure of arterial segments to Ang II is considered to lead to tachyphylaxis (27), each ring was only tested in one experiment and was not reused.

Contractions and intracellular $\mathrm{Ca}^{2+}$ concentration of mesenteric arteries. At 48 weeks after the transplantation surgery, the rats were intraperitoneally injected with $3 \%$ sodium pentobarbital $(50 \mathrm{mg} / \mathrm{kg})$. The fourth-order mesenteric arterial branches were isolated under a microscope and cut into 3-mm segments. These segments were mounted in a Multi Myograph system (Danish Myo Technology A/S, Midtjylland, Denmark) containing modified Krebs solution equilibrated with $95 \% \mathrm{O}_{2}$ and $5 \% \mathrm{CO}_{2}$ at $37^{\circ} \mathrm{C}$. Following a 60 -min equilibration period, the segments were stretched to the optimal resting tension, and then stimulated with increasing concentrations of Ang II $\left(10^{-11}-10^{-5} \mathrm{~mol} / \mathrm{l}\right)$ in one-half log increments. Losartan $(10 \mu \mathrm{mol} / \mathrm{l})$ and PD-123319 $(10 \mu \mathrm{mol} / \mathrm{l})$ were each used to pretreat the segments for $30 \mathrm{~min}$ prior to the addition of Ang II. The contractile tension was measured and recorded using a Power-Lab system with Chart 5 software (both from ADInstruments), which was normalized by the maximum contraction elicited by the stimulation of the $60 \mathrm{mmol} / \mathrm{l} \mathrm{KCl}$. Each arterial segment was only tested once.

The fourth-order mesenteric arterial branches were isolated under a microscope and cut into 3-mm segments. These segments were mounted and pressurized in an organ chamber (Living Systems Instrumentation, Burlington, VT, USA) in a darkened room. The intracellular $\mathrm{Ca}^{2+}$ concentration $\left(\left[\mathrm{Ca}^{2+}\right]_{\mathrm{i}}\right)$ of each segment was measured using a Radiance 2100 confocal system with the acetoxymethyl ester of Fura-2 (Fura-2 AM; Calbiochem, San Diego, CA, USA) as a $\left[\mathrm{Ca}^{2+}\right]_{i}$ indicator. The vessel $\left[\mathrm{Ca}^{2+}\right]_{i}$ was determined on the basis of the fluorescence ratio of Fura-2 AM at wavelengths of 340 and $380 \mathrm{~nm}$. The arteries were superfused with modified Hanks' solution and pressurized to $45 \mathrm{mmHg}$ with a mixture of $95 \% \mathrm{O}_{2}$ and $5 \% \mathrm{CO}_{2}$ at $37^{\circ} \mathrm{C}$. Following $60 \mathrm{~min}$ incubation with Fura-2 AM loading, the constriction and $\left[\mathrm{Ca}^{2+}\right]$ i of the mesenteric artery were simultaneously monitored in the same vessel segment. The pressurized arteries were stimulated by a single Ang II concentration $\left(10^{-7} \mathrm{~mol} / \mathrm{l}\right)$ until the maximal reduction in arterial diameter was achieved. Additionally, losartan $(10 \mu \mathrm{mol} / \mathrm{l})$ or PD-123319 $(10 \mu \mathrm{mol} / \mathrm{l})$ was used to pretreat the arteries for $30 \mathrm{~min}$ prior to the addition of Ang II. The mesenteric artery diameter and $\left[\mathrm{Ca}^{2+}\right]_{\mathrm{i}}$ signal were determined from the ratio of fluorescence at 340 and $380 \mathrm{~nm}$ and recorded with a SoftEdge Data Acquisition Subsystem (IonOptix, Westwood, MA, USA). The results were normalized using the maximum contraction induced by $60 \mathrm{mmol} / 1 \mathrm{KCl}$. 
Western blot analysis. At 48 weeks after the transplantation surgery, protein samples were routinely extracted from the aortic and mesenteric arteries, which were routinely homogenized in NP-40 lysis buffer (Thermo Fisher Scientific, Inc., Waltham, MA, USA) with freshly added protease inhibitors using sonication. Samples with an equal protein content $(80 \mu \mathrm{g} /$ lane) were subjected to electrophoresis using a $0.1 \%$ sodium dodecylsulfate (SDS) and 10\% polyacrylamide separating gel with $4 \%$ polyacrylamide stacking gel. The proteins were then transferred to an Immobilon $\mathrm{P}$ polyvinyldifluoride membrane (EMD Millipore, Billerica, MA, USA). The membrane was blocked with Tris-buffered phosphate-buffered saline (PBS) containing 5\% bovine serum albumin (BSA; Sigma-Aldrich; Merck KGaA) plus $0.1 \%$ v/v Tween-20 with gentle shaking for $1 \mathrm{~h}$ at room temperature prior to incubation with primary antibodies overnight at $4^{\circ} \mathrm{C}$. The antibodies were rabbit polyclonal antibodies directed against $\mathrm{AT}_{1} \mathrm{R}$ (sc-1173; 1:500), $\mathrm{AT}_{2} \mathrm{R}$ (sc-9040; 1:1,000), cyclic AMP-responsive element-binding protein 1 (CREB-1; sc-58; 1:500), estrogen receptor (ER)- $\alpha$ (sc-544; 1:500) and ER- $\beta$ (sc-8974; 1:500) (all from Santa Cruz Biotechnology, Inc., Dallas, TX, USA), respectively. The membranes were washed three times for $10 \mathrm{~min}$ in a solution of TBS and Tween-20, and then incubated at room temperature for $10 \mathrm{~min}$ with a horseradish peroxidaseconjugated goat anti-rabbit secondary antibody (1:5,000; A0545; Sigma-Aldrich; Merck KGaA). The proteins were visualized using an ECL reagent (Amersham; GE Healthcare Life Sciences, Little Chalfont, UK) with exposure to an X-ray film. The $\beta$-actin protein (sc-47778, 1:1,000) was blotted in the same membrane as internal control for the normalization of band density. Results were quantified and analyzed using a Kodak electrophoresis documentation \& analysis system, and 1D image analysis software version 2.0 (Kodak, Rochester, NY, USA).

Reverse transcription-quantitative polymerase chain reaction $(R T-q P C R)$. At 48 weeks after the transplantation surgery, total tissue RNA was routinely isolated from the aortic and mesenteric arteries, by homogenization with TRIzol reagent (Invitrogen; Thermo Fisher Scientific, Inc.), followed by addition of chloroform. After the homogenate was separated by centrifugation at $12,000 \mathrm{x}$ g for $10 \mathrm{~min}$ at $4^{\circ} \mathrm{C}$, RNA was precipitated from the upper aqueous layer with isopropanol from the tissues. First strand cDNA synthesis was then performed using MMLV-RT reverse transcriptase (Invitrogen; Thermo Fisher Scientific, Inc.). cDNA synthesis reaction was performed under $50-70^{\circ} \mathrm{C}$ for $30 \mathrm{~min}$ and then heating at $90^{\circ} \mathrm{C}$ for $5 \mathrm{~min}$. qPCR analysis was then used to evaluate the gene expression of $\mathrm{AT}_{1 \mathrm{a}} \mathrm{R}, \mathrm{AT}_{2} \mathrm{R}, \mathrm{CREB}-1, \mathrm{ER}-\alpha$ and ER- $\beta$. Glyceraldehyde 3-phosphate dehydrogenase (GAPDH) was used as an internal reference and serial dilutions of the positive control were performed on each plate to create a standard curve. The primer sequences were as follows: $\mathrm{AT}_{1 \mathrm{a}} \mathrm{R}$ forward, 5'-GCAGCCTCTGACTAAATGGC-3' and reverse, 5'-TCC ATCCAGCTCCTGACTCT-3'; AT 2 R forward, 5' CGGTGG CTTGCCGTTTCTT-3' and reverse, 5'-GACTCATTGGTG CCAGTTGC-3'; CREB-1-1 forward, 5' ACTCAGCCGGGT ACTACCAT-3' and reverse, 5'-ACTCAGCCGGGTACTACC AT-3'; ER- $\alpha$ forward, 5' GCCACTCGATCATTCGAGCA-3' and reverse, 5'-CACCCTGCTGGTTCAAAAGC-3'; ER- $\beta$ forward, 5' CTGGACAGGGATGAGGGGAA-3' and reverse, 5'-CGAAGCGTGTGAGCATTCAG-3'; GAPDH forward, 5'
GGTGGTCTCCACGGACTTTA-3' and reverse, 5'-CAAGGA GGGGCCTTTATTTC-3'. qPCR was performed in a Bio-Rad iCycler iQ Real-Time PCR system (Bio-Rad Laboratories, Inc., Hercules, CA, USA) with a $25-\mu 1$ reaction system in a $96-$ well plate (One-Step SYBR ${ }^{\circledR}$ PrimeScript $^{\mathrm{TM}}$ RT-PCR kit II; cat. no. RR086A; Takara Bio, Inc., Shiga, Japan). The thermocycling conditions were as follows: $42^{\circ} \mathrm{C}$ for $30 \mathrm{~min}, 95^{\circ} \mathrm{C}$ for $15 \mathrm{~min}$, followed by 40 cycles of $95^{\circ} \mathrm{C}$ for $20 \mathrm{sec}, 56^{\circ} \mathrm{C}$ for $1 \mathrm{~min}$ and $72^{\circ} \mathrm{C}$ for $20 \mathrm{sec}$. The target gene quantity was normalized to the reference GAPDH to obtain the relative quantification cycle $(\Delta \mathrm{Cq})$. The $2^{-\Delta \Delta \mathrm{Cq}}$ method (28) was then used to determine the relative target gene expression for each group.

Methylation-specific $q P C R(M S-q P C R)$. DNA methylation of $\mathrm{CpG}$ sites at the promoter region of the rat vascular $\mathrm{AT}_{1 \mathrm{a}} \mathrm{R}$ gene was evaluated using MS-qPCR. At 48 weeks after the transplantation surgery, genomic DNA was isolated from the aortic or mesenteric arteries using an GenElute Mammalian Genomic DNA Miniprep kit (Sigma-Aldrich; Merck KGaA), and purified with a Wizard DNA clean up system (Promega Corporation, Madison, WI, USA). This involves treatment with sodium bisulfite, which converts cytosine residues to uracil residues but leaves the methylated cytosines at $\mathrm{CpG}$ unchanged. Following denaturation of the DNA with $2 \mathrm{M}$ $\mathrm{NaOH}$ at $42^{\circ} \mathrm{C}$ for $15 \mathrm{~min}$, the DNA was treated with sodium bisulfite at $55^{\circ} \mathrm{C}$ for $16 \mathrm{~h}$ and then used as the template for MS-qPCR. Specific primers were designed (CpG site-809 forward, 5'-AGGGTTGGAATTTGTAGAGTAGC-3' and reverse, 5'-GAATAAAACAAAACTCAAACCACG-3'; CpG site-725 forward,5'-GAGGGTTGGAATTTGTAGAGTAGC-3' and reverse, 5'-GAATAAAACAAAACTCAAACCACG-3'; CpG site-484 forward, 5'-GGTTGGAATTTGTAGA GTAGCGA-3' and reverse, 5'-GAATAAAACAAAACTCA AACCACG-3'; CpG site-150 forward, 5'-GAGGGTTGGAA TTTGTAGAGTAGC-3' and reverse, 5'-CCCCGATAAT CGATAATCGA-3'; and CpG site-96 forward, 5'-TGAGGGT TGGAATTTGTAGAGTAGT-3' and reverse, 5'-CCACCCC AATAATCAATAATCAA-3') to amplify the target regions with un-methylated $\mathrm{CpG}$ via the detection of uracils and those with methylated $\mathrm{CpG}$ via the detection of cytosines, using GADPH as an internal reference. MS-qPCR was conducted using an iCycler Real-Time PCR system. Data are presented as the percentage methylation of the target region as follows: Methylation $(\%)=$ methylated $\mathrm{CpG} /($ methylated $\mathrm{CpG}$ + un-methylated CpG) x100.

Chromatin immunoprecipitation assay (ChIP). At 48 weeks after the transplantation surgery, ChIP of the aortic and mesenteric arteries was conducted using a ChIP-IT ${ }^{\circledR}$ kit (Active Motif, Carlsbad, CA, USA) according to the manufacturer's protocol. This involved setting up the immunoprecipitation reaction with sonicated chromatin and sequentially adding CHIP buffer and protease inhibitor cocktail to the $1.5-\mathrm{ml}$ microcentrifuge tube ( $\geq 200$ ng chromatin per CHIP reaction). Rabbit monoclonal anti-CREB-1-1 (ab-31387; 1:500), anti-ER- $\alpha$ (ab-32063; 1:200) and anti-ER- $\beta$ (ab-3577; 1:500) (all from Abcam, Cambridge, MA, USA) were added and the reaction mixture was incubated overnight at $4^{\circ} \mathrm{C}$. The next day, following extensive blocking in $0.5 \% \mathrm{BSA}$, protein $\mathrm{G}$ agarose beads were added to the mixture and incubated for $3 \mathrm{~h}$. Following washing and the reversal 
Table I. Blood biochemical indices at 48 weeks after surgery.

\begin{tabular}{lrr}
\hline Blood values & \multicolumn{1}{c}{ Con } & \multicolumn{1}{c}{$\mathrm{RT}$} \\
\hline Osm $(\mathrm{mOsm} / \mathrm{kg})$ & $292.13 \pm 2.11$ & $293.05 \pm 2.29$ \\
{$\left[\mathrm{Na}^{+}\right](\mathrm{mmol} / \mathrm{l})$} & $136.86 \pm 1.17$ & $137.15 \pm 0.87$ \\
{$\left[\mathrm{~K}^{+}\right](\mathrm{mmol} / \mathrm{l})$} & $4.11 \pm 0.51$ & $4.16 \pm 0.57$ \\
$\mathrm{pH}$ & $7.40 \pm 0.02$ & $7.41 \pm 0.01$ \\
$\mathrm{pCO}_{2}$ & $37.31 \pm 1.21$ & $37.41 \pm 1.26$ \\
$\mathrm{pO}_{2}$ & $105.77 \pm 2.19$ & $106.13 \pm 2.31$ \\
$\mathrm{SO}_{2} \%$ & $96.55 \pm 1.33$ & $96.13 \pm 2.03$ \\
$\mathrm{Hct}(\%)$ & $35.51 \pm 1.01$ & $35.13 \pm 1.27$ \\
$\mathrm{Glu}^{(\mathrm{mmol} / \mathrm{l})}$ & $7.51 \pm 0.32$ & $7.47 \pm 0.37$ \\
$\mathrm{Lac}(\mathrm{mmol} / \mathrm{l})$ & $1.53 \pm 0.11$ & $1.49 \pm 0.23$
\end{tabular}

Con, control group; RT, renal transplantation group; Osm, osmolality; $\left[\mathrm{Na}^{+}\right]$, sodium ion concentration, $\left[\mathrm{K}^{+}\right]$, potassiun ion concentration; $\mathrm{pCO}_{2}$, partial pressure of carbon dioxide; $\mathrm{pO}_{2}$, partial pressure of oxygen; $\mathrm{sO}_{2}$, oxygen saturation; Hct, hematocrit; Glu, glucose; Lac, lactate.

of cross-links, DNA was recovered and purified. Finally, the SYBR-Green quantitative PCR was performed. Data are presented as the percentage of input.

Statistical analysis. All data are expressed as the mean \pm standard deviation. BP and vascular contractility data were analyzed using repeated-measures analysis of variance (ANOVA) with Tukey's post hoc tests. For analysis of the differences of mRNA levels between groups, statistical significance was accepted $(\mathrm{P}<0.05)$ when the ratio of $2^{-\Delta \Delta C q}$ was $>1.7$. One-way ANOVA was used for other data to evaluate the differences among groups. $\mathrm{P}<0.05$ was considered to indicate a statistically significant result. SPSS statistical software (version 18; SPSS, Inc., Chicago, IL, USA) was used to conduct the statistical analyses.

\section{Results}

Blood biochemical indices. At 48 weeks after the transplantation surgery, no significant differences in blood biochemical indices, including $\mathrm{pH}, \mathrm{pCO}_{2}, \mathrm{pO}_{2}, \mathrm{sO}_{2} \%$, Hct, the concentrations of Glu and $\mathrm{Lac},\left[\mathrm{Na}^{+}\right],\left[\mathrm{K}^{+}\right]$and plasma osmolality were detected between the RT and control groups using the Nova eleven-electrode analyzer (Nova Biomedical) (Table I).

Concentrations of Ang II in plasma and blood vessels. At 48 weeks after the transplantation surgery, the plasma concentration of Ang II in the RT group was significantly lower compared with that in the control group $(\mathrm{P}<0.05$; Fig. 1A). However, in the aorta and mesenteric artery tissues, the concentrations of Ang II were significantly higher in RT group compared with the control group $(\mathrm{P}<0.05$; Fig. 1B and $\mathrm{C})$.

Basal BP and Ang II-induced BP response. At 48 weeks after the transplantation surgery, the basal arterial SBP, DBP and MAP exhibited no significant difference between the RT and control groups for rats in the conscious state (Fig. 2A). Following the intravenous administration of Ang II, the time-dependent arterial $\mathrm{BP}$ response was in the range of
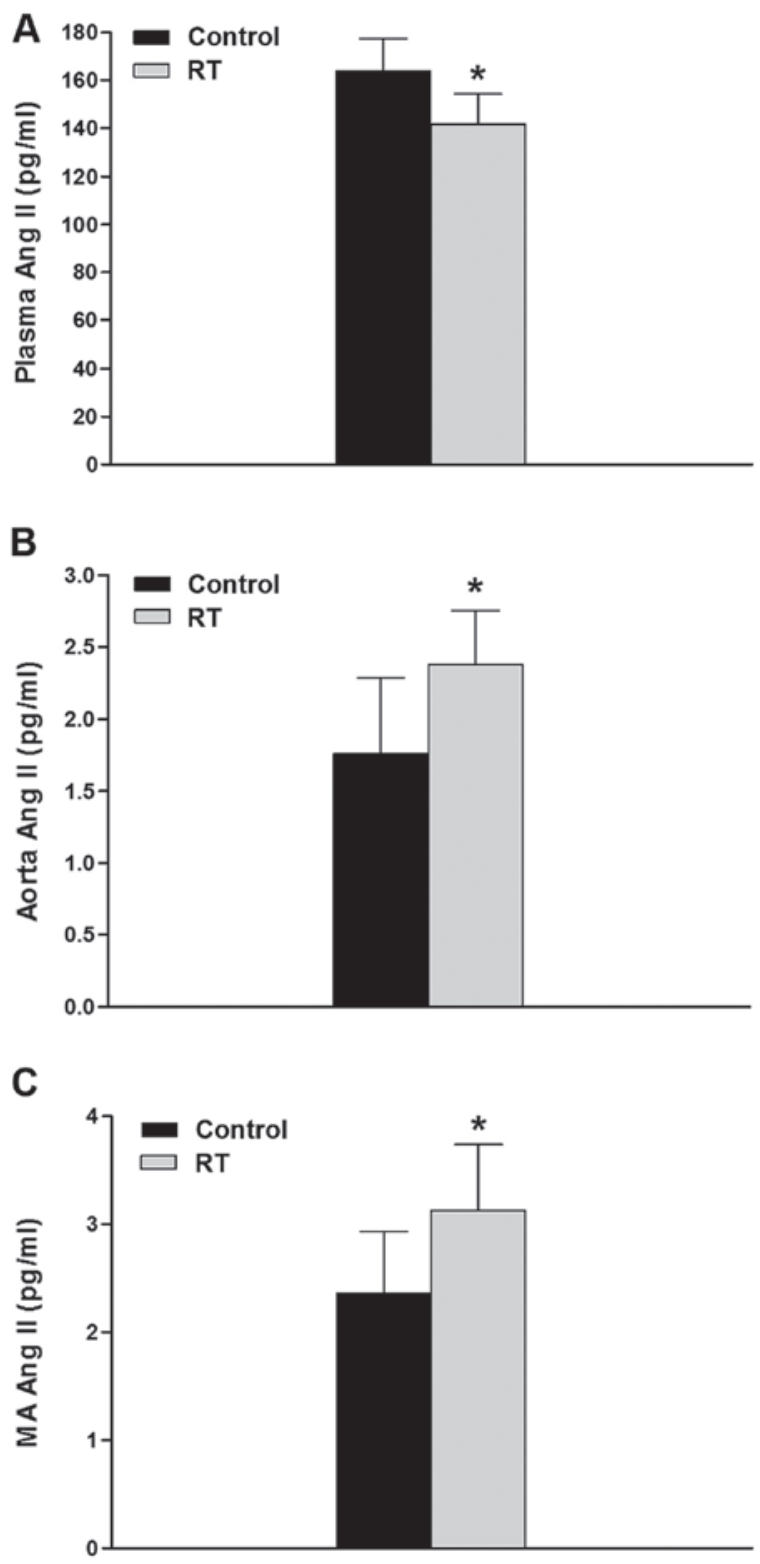

Figure 1. Concentrations of Ang II in plasma and blood vessels at 48 weeks after transplantation. (A) The plasma concentration of Ang II in the RT group was significantly decreased compared with that in the Con group. In the (B) aorta and (C) MA, the concentrations of Ang II were significantly increased in the RT group compared with the Con group. Values are presented as the mean \pm standard deviation ( $\mathrm{n}=6$ per group). ${ }^{*} \mathrm{P}<0.05$ vs. Con. Ang II, angiotensin II; RT, renal transplantation; MA, mesenteric arteries; Con, control.

several min. The Ang II-induced arterial SBP, DBP and MAP values in the RT group were significantly increased compared with those in the control group $(\mathrm{P}<0.05$; Fig. $2 \mathrm{~A})$.

Following pretreatment with the selective $\mathrm{AT}_{1} \mathrm{R}$ antagonist losartan, the time-dependent elevation of arterial SBP, DBP and MAP induced by Ang II was largely diminished and exhibited no significant difference between the RT and control groups (Fig. 2B). However, following pretreatment with the selective $\mathrm{AT}_{2} \mathrm{R}$ antagonist $\mathrm{PD}-123319$, the time-dependent elevation of arterial SBP, DBP and MAP induced by Ang II was not significantly changed in the RT and control groups (Fig. 2C).

Ang II-induced contraction of the aorta. At 48 weeks after the transplantation surgery, the aortal contractions induced by 

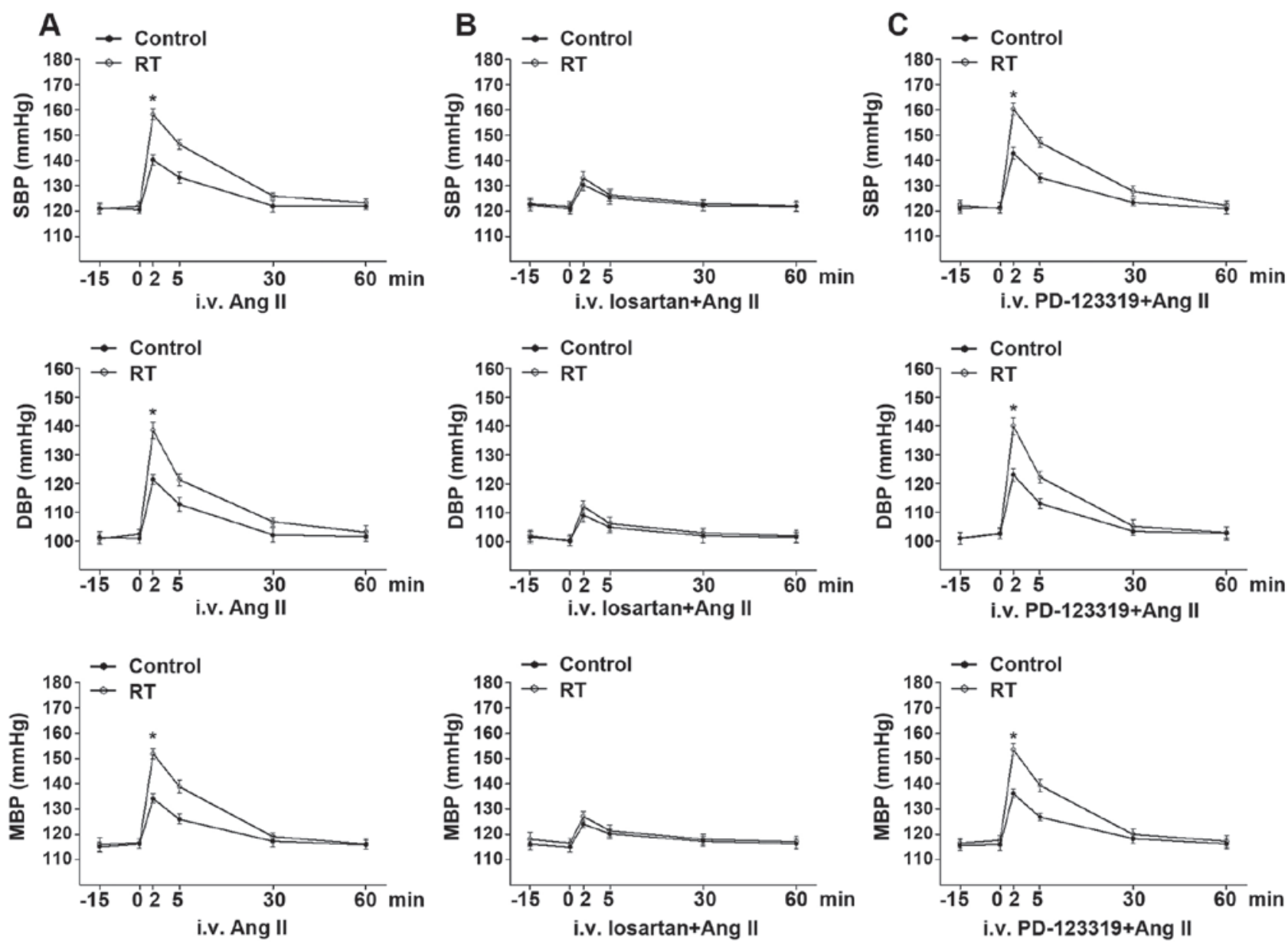

Figure 2. Basal BP and Ang II-induced BP response at 48 weeks after transplantation surgery. (A) In the conscious state, the basal arterial BP including SBP, DBP and MAP exhibited no significant difference between the RT and control groups. In addition, Ang II-induced SBP, DBP and MAP in the RT group were significantly enhanced compared with those in the control. (B) Following pretreatment with the selective $\mathrm{AT}_{1} \mathrm{R}$ antagonist losartan, the time-dependent elevation of SBP, DBP and MAP induced by Ang II was largely diminished and exhibited no significant difference between the RT and control groups. (C) Following pretreatment with the selective $\mathrm{AT}_{2} \mathrm{R}$ antagonist PD-123319, the time-dependent elevation of SBP, DBP and MAP induced by Ang II was not significantly changed in the RT and control groups. Values are presented as the mean \pm standard deviation ( $\mathrm{n}=6$ per group). " $\mathrm{P}<0.05$ vs. control. $\mathrm{BP}$, blood pressure; Ang II, angiotensin II; SBP, systolic BP; DBP, diastolic BP; MAP, mean BP; RT, renal transplantation; $\mathrm{AT}_{1} \mathrm{R}$, angiotensin II receptor type 1; $\mathrm{AT}_{2} \mathrm{R}$, angiotensin II receptor type 2; i.v., intravenous.

Ang II $\left(10^{-11}-10^{-5} \mathrm{~mol} / \mathrm{l}\right)$ were measured (Fig. 3). The contractions of the RT group were significantly increased in tension compared with those of the control $(\mathrm{P}<0.05$; Fig. 3A). In addition, following pretreatment with losartan, the Ang II-induced aortal contractions in the RT and control groups were almost completely eradicated (Fig. 3A). However, pretreatment with PD-123319 did not significantly affect the Ang II-induced aortal contractions in the RT and control groups (Fig. 3C).

Vascular contractility of the aortas in the absence of endothelium was examined to determine the effects of the endothelium in vasodilation. Without endothelium, the Ang II-induced aortal vasoconstrictions in the RT and control groups were significantly increased compared with those in the endothelium-intact aortas $(\mathrm{P}<0.05$; Fig. 3B). However, Ang II-induced aortal vasoconstrictions in the RT and control groups were almost completely abolished by losartan, but hardly altered by PD-123319 in the absence of endothelium (Fig. 3B and D).

Ang II-induced contractions and $\left[\mathrm{Ca}^{2+}\right]_{i}$ in small mesenteric arteries. At 48 weeks after transplantation surgery, the contractions of the mesenteric arteries induced by Ang II $\left(10^{-11}-10^{-5} \mathrm{~mol} / \mathrm{l}\right)$ were measured (Fig. 4). The Ang II-induced contractions of the mesenteric arteries of the RT group were significantly increased in tension compared with those of the control $(\mathrm{P}<0.05$; Fig. 4A). In addition, following pretreatment with losartan, the Ang II-induced contractions in the mesenteric arteries of the RT and control groups were eliminated (Fig. 4A). However, pretreatment with PD-123319 did not have a significant effect on the Ang II-induced contractions in the mesenteric arteries of the RT and control groups (Fig. 4C).

The vasoconstriction of the mesenteric arteries in the absence of endothelium was examined to further analyze the effects of the endothelium in vasodilation. When the endothelium was absent, the Ang II-induced vasoconstriction of the mesenteric arteries was significantly increased in the RT and control groups compared with the endothelium-intact arteries ( $\mathrm{P}<0.05$; Fig. 4B). However, as in the presence of endothelium, in the absence of endothelium, the Ang II-induced vascular contractility of the mesenteric arteries in the RT and control groups was largely eradicated by losartan, but not markedly changed by PD-123319 (Fig. 4B and D). 

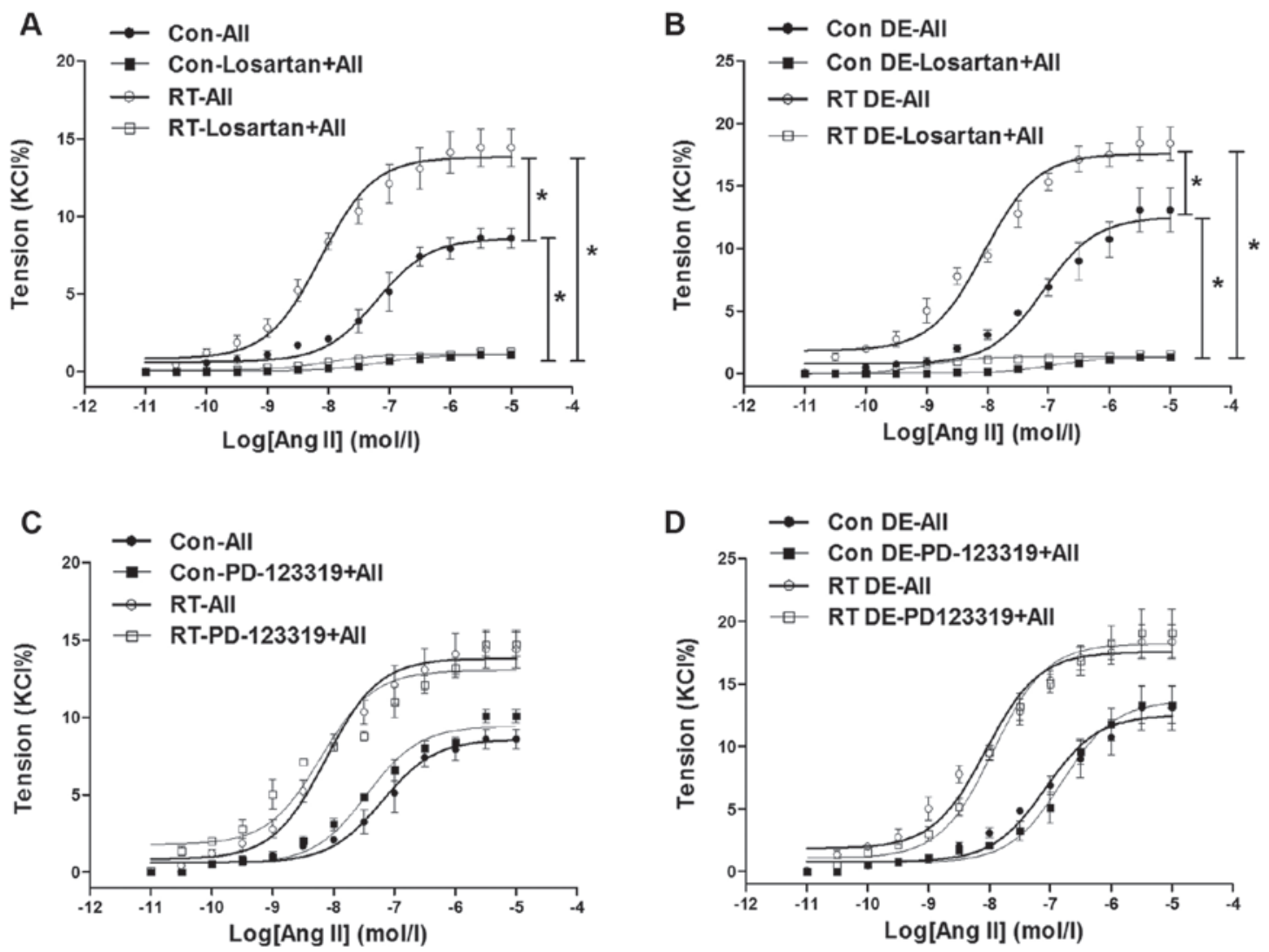

Figure 3. Ang II-induced contractions in rat aortas at 48 weeks after transplantation surgery. (A) In the presence of endothelium, Ang II-induced contractions of aortas of the RT group were significantly increased compared with those of the control group. In addition, following pretreatment with losartan, Ang II-induced contractions of the aortas of the RT and control groups were almost eradicated. (B) Without endothelium, Ang II-induced vasoconstrictions in aortas of the RT and control groups were significantly increased compared with those in endothelium-intact aortas. Without endothelium, Ang II-induced vasoconstrictions in aortas of the RT and control groups were almost eradicated by losartan. (C) In the presence of endothelium, following pretreatment with PD-123319, Ang II-induced contractions in aortas of the RT and control groups were not significantly changed. (D) Without endothelium, Ang II-induced vasoconstrictions in aortas of the RT and control groups were not significantly altered by PD-123319. Values are presented as the mean \pm standard deviation ( $\mathrm{n}=6$ per group). ${ }^{*} \mathrm{P}<0.05$ as indicated. Ang II (AII), angiotensin II; RT, renal transplantation; Con, control.

When the pressurized mesenteric arteries were stimulated with Ang II $\left(10^{-7} \mathrm{~mol} / \mathrm{l}\right)$, the reductions in diameter of the arteries were observed to be closely associated with increases of $\left[\mathrm{Ca}^{2+}\right]_{\mathrm{i}}$. The results of the organ chamber experiments demonstrated that the vascular constriction and $\left[\mathrm{Ca}^{2+}\right]$ ${ }_{i}$ increases in these arteries were significantly enhanced in the RT group compared with the control group $(\mathrm{P}<0.05$; Fig. 5A). In addition, following pretreatment with losartan, the Ang II-induced vascular constriction and increase in $\left[\mathrm{Ca}^{2+}\right]_{\mathrm{i}}$ in the RT and control groups were almost completely eradicated (Fig. 5B). However, pretreatment with PD-123319 did not significantly alter the Ang II-induced vascular constriction and $\left[\mathrm{Ca}^{2+}\right]_{\mathrm{i}}$ increase in the RT and control groups (Fig. 5C).

Expression of $A T_{1 a} R$ and $A T_{2} R$ mRNA in blood vessels. To investigation whether there was an association between the Ang II-induced cardiovascular responses and changes in $\mathrm{AT}_{1} \mathrm{R}$ and $\mathrm{AT}_{2} \mathrm{R}$, the expression of these receptors in the aorta and mesenteric arteries at the genetic level was detected using RT-qPCR. In rodents, two subtypes of the $\mathrm{AT}_{1} \mathrm{R}$ gene have been identified, namely $\mathrm{AT}_{1 \mathrm{a}} \mathrm{R}$ and $\mathrm{AT}_{1 \mathrm{~b}} \mathrm{R}$, the former of which is the major subtype localized in blood vessels (29). At 48 weeks after the transplantation surgery, the expression levels of $\mathrm{AT}_{1 \mathrm{a}} \mathrm{R}$ mRNA in the aorta and mesenteric arteries of the RT group were significantly increased compared with those in the control group $(\mathrm{P}<0.05$; Fig. 6A). However, the mRNA expression levels of $\mathrm{AT}_{2} \mathrm{R}$ in the aorta and mesenteric arteries exhibited no significant difference between the RT and control groups (Fig. 6B).

Protein levels of $A T_{1} R$ and $A T_{2} R$ in blood vessels. The polypeptides expressed by the $\mathrm{AT}_{1 \mathrm{a}} \mathrm{R}$ and $\mathrm{AT}_{1 \mathrm{~b}} \mathrm{R}$ genes cannot be distinguished at the protein level. Western blot analysis was used to evaluate the protein expression of $\mathrm{AT}_{1} \mathrm{R}$ and $\mathrm{AT}_{2} \mathrm{R}$ in the blood vessels. At 48 weeks after transplantation surgery, the protein levels of $\mathrm{AT}_{1} \mathrm{R}$ in the aorta and mesenteric arteries of the RT group were significantly increased compared with that in the control group ( $\mathrm{P}<0.05$; Fig. 7A). However, no significant difference in the $\mathrm{AT}_{2} \mathrm{R}$ protein levels of the aorta and mesenteric arteries were detected between the RT and control groups (Fig. 7B).

$D N A$ methylation of $C p G$ loci in the $A T_{1 a} R$ gene promoter region in blood vessels. To evaluate the effects of DNA methylation patterns on the transcriptional activity of the $\mathrm{AT}_{1 \mathrm{a}} \mathrm{R}$ gene, five sequence-specific transcription factor binding sites containing $\mathrm{CpG}$ loci were identified in the promoter region of the $\mathrm{AT}_{1 \mathrm{a}} \mathrm{R}$ gene sequence from the rodent gene bank. The $\mathrm{CpG}$ sites at loci -809 , $-725,-484,-150$ and -96 upstream of the transcription start site of 

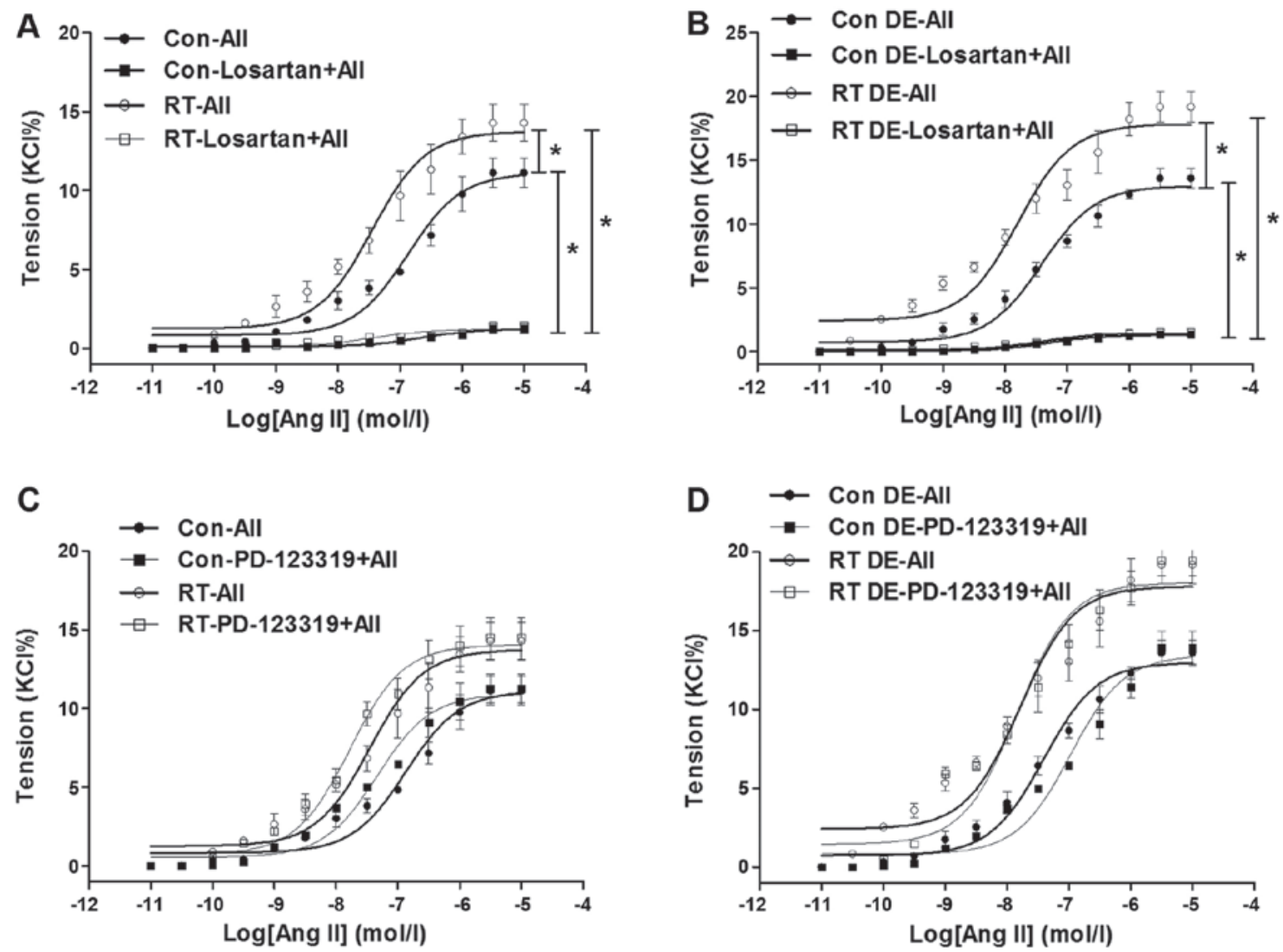

Figure 4. Ang II-induced contractions in mesenteric arteries at 48 weeks after transplantation surgery. (A) In the presence of endothelium, Ang II-induced contractions in mesenteric arteries of the RT group were significantly increased compared with those of the control. In addition, following pretreatment with losartan, Ang II-induced contractions in mesenteric arteries of the RT and control groups were almost eradicated. (B) Without endothelium, Ang II-induced vasoconstrictions in mesenteric arteries of the RT and control groups were significantly increased compared with those in endothelium-intact arteries. Without endothelium, Ang II-induced vasoconstrictions in mesenteric arteries of the RT and control groups were almost eradicated by losartan. (C) In the presence of endothelium, following pretreatment with PD-123319, Ang II-induced contractions in mesenteric arteries of the RT and control groups were not significantly changed. (D) Without endothelium, Ang II-induced vasoconstrictions in mesenteric arteries of the RT and control groups were not significantly altered by PD-123319. Value are the mean \pm standard deviation ( $\mathrm{n}=6$ per group). ${ }^{\mathrm{P}}<0.05$ as indicated. Ang II (AII), angiotensin II; RT, renal transplantation; Con, control.
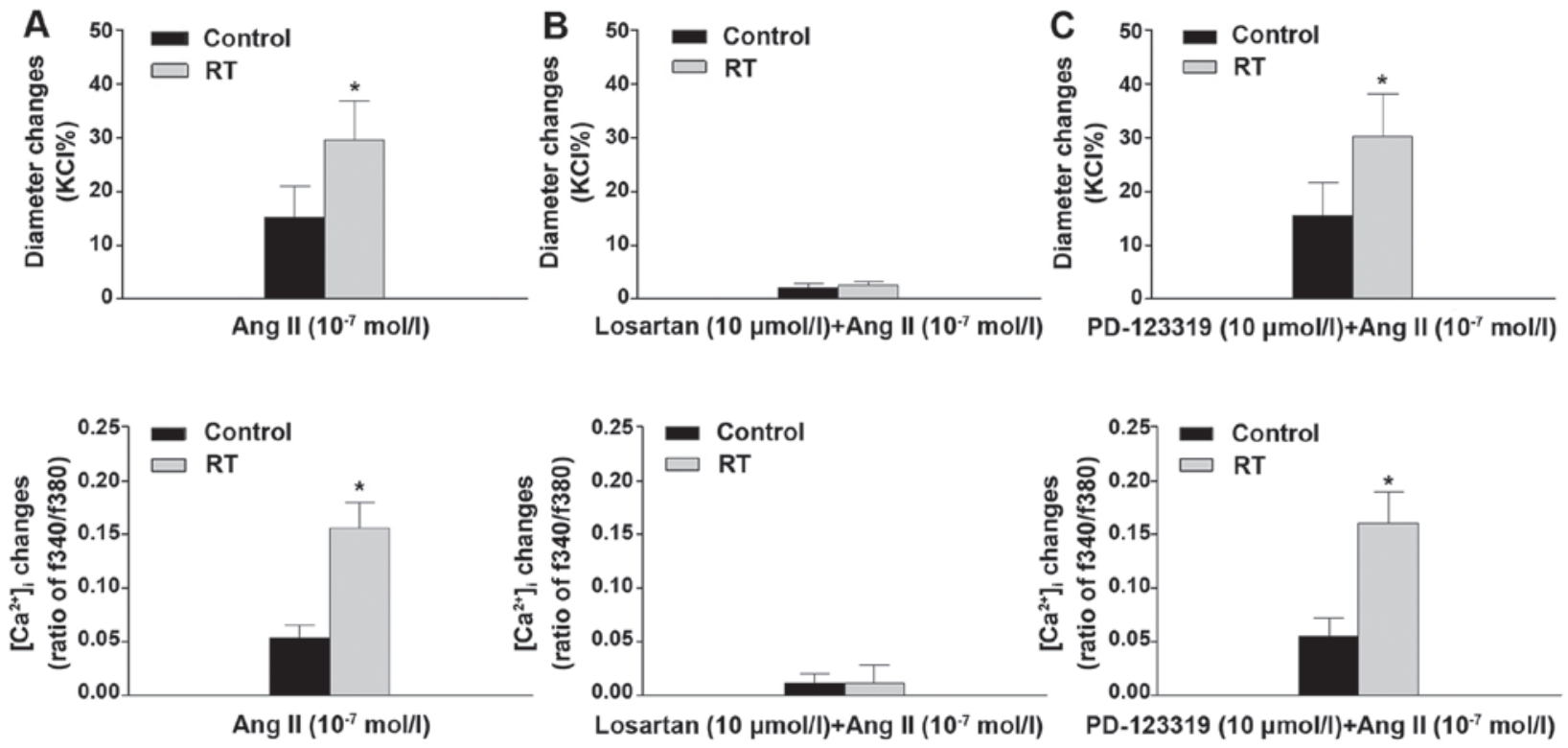

Figure 5. Changes of $\left[\mathrm{Ca}^{2+}\right]_{\mathrm{i}}$ induced by Ang II in pressurized mesenteric arteries at 48 weeks after transplantation. (A) The diameter reduction and $\left[\mathrm{Ca}^{2+}\right]_{\mathrm{i}}$ increase in mesenteric arteries induced by Ang II were significantly enhanced in the RT group compared with the control. (B) Following pretreatment with losartan, the diameter reduction and $\left[\mathrm{Ca}^{2+}\right]_{\mathrm{i}}$ increase in mesenteric arteries induced by Ang II were almost eradicated in the RT and control groups. (C) Pretreatment with PD-123319 did not significantly change the diameter reduction and $\left[\mathrm{Ca}^{2+}\right]_{\mathrm{i}}$ increase in mesenteric arteries induced by Ang II in the RT and control groups. Values are presented as the mean \pm standard deviation ( $\mathrm{n}=6$ per group). ${ }^{*} \mathrm{P}<0.05$ vs. control. $\left[\mathrm{Ca}^{2+}\right]_{\mathrm{i}}$ intracellular calcium ion concentration; Ang II, angiotensin II; RT, renal transplantation; Con, control. 


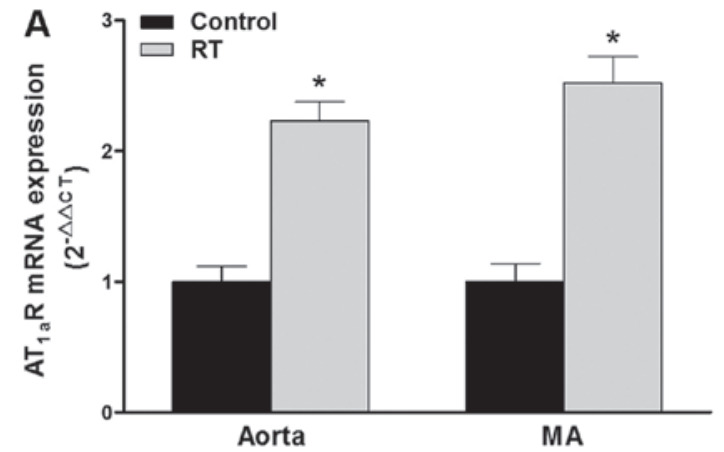

B

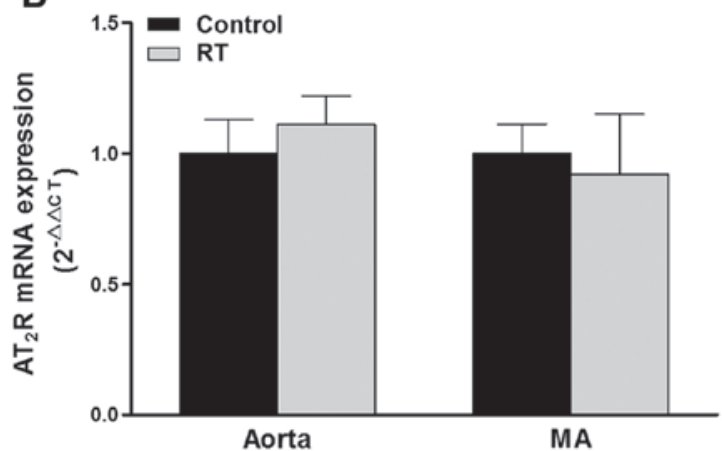

Figure 6. mRNA expression levels of $\mathrm{AT}_{12} \mathrm{R}$ and $\mathrm{AT}_{2} \mathrm{R}$ in blood vessels at 48 weeks after transplantation surgery. (A) mRNA expression of $\mathrm{AT}_{\mathrm{la}} \mathrm{R}$ in the aorta and MA of the RT group were significantly increased compared with those of the control. (B) mRNA expression of $\mathrm{AT}_{2} \mathrm{R}$ in the aorta and MA exhibited no significant difference between the RT and control groups. Values are presented as the mean \pm standard deviation ( $\mathrm{n}=6$ per group), ${ }^{*} \mathrm{P}<0.05$ vs. control. $\mathrm{AT}_{1 \mathrm{a}} \mathrm{R}$, angiotensin II receptor type $1 \mathrm{a} ; \mathrm{AT}_{2} \mathrm{R}$, angiotensin II receptor type 2; MA, mesenteric arteries; RT, renal transplantation; Con, control.

the $\mathrm{AT}_{\mathrm{la}} \mathrm{R}$ gene correspond to the transcription factor binding sites of erythroid transcription factor (GATA-1), specificity protein 1 (Sp-1), ER- $\alpha / \beta$, CREB-1 and Sp-1, respectively. At 48 weeks after the transplantation surgery, MS-qPCR analysis of the aorta and mesenteric arteries was conducted. The results indicated that the DNA methylation levels of CpG loci at the ER- $\alpha / \beta(-484)$ and CREB-1 (-150) transcription factor binding sites in the $\mathrm{AT}_{1 \mathrm{a}} \mathrm{R}$ gene promoter region were significantly decreased in the RT group compared with the control group ( $\mathrm{P}<0.05$; Fig. 8). However, the DNA methylation status of the CpG loci at the GATA-1 (-809) and Sp-1 (-725 and -96) transcription factor binding sites of the $\mathrm{AT}_{1 \mathrm{a}} \mathrm{R}$ gene promoter region exhibited no significant difference between the RT and control groups (Fig. 8).

Binding capacity of $C R E B-1$ and $E R-\alpha / \beta$ to the $A T_{1 a} R$ gene promoter region in blood vessels. To evaluate the functions of CREB- 1 and ER- $\alpha / \beta$ in the control of the transcriptional activity of the $\mathrm{AT}_{1 \mathrm{a}} \mathrm{R}$ gene, the binding affinities of CREB-1 and $E R-\alpha / \beta$ for the specific sequences in the promoter region of the $\mathrm{AT}_{1 \mathrm{a}} \mathrm{R}$ gene were determined by ChIP assays of the blood vessels 48 weeks after transplantation. The results demonstrated that in the aorta and mesenteric arteries of the RT group, the binding affinities of CREB-1 for the $\mathrm{AT}_{1 \mathrm{a}} \mathrm{R}$ gene promoter were significantly increased compared with those in the control group $(\mathrm{P}<0.05$; Fig. 9A). However, the binding affinities of ER- $\alpha$ and ER- $\beta$ for the $\mathrm{AT}_{1 \mathrm{a}} \mathrm{R}$ gene promoter in the aorta and mesenteric arteries were significantly decreased in the RT group compared with the control $(\mathrm{P}<0.05$; Fig. 9B and $\mathrm{C})$.
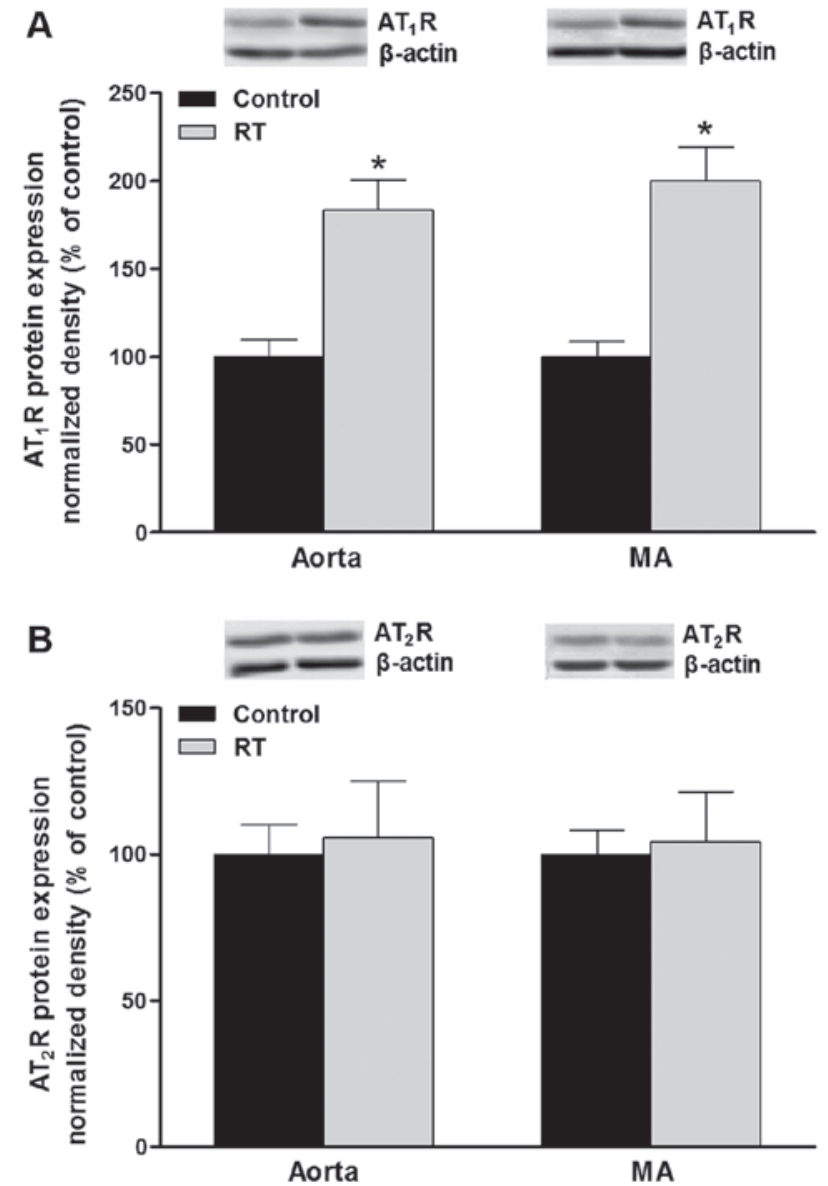

Figure 7. Protein expression levels of $\mathrm{AT}_{1} \mathrm{R}$ and $\mathrm{AT}_{2} \mathrm{R}$ in blood vessels at 48 weeks after transplantation surgery. (A) Protein expression levels of $A_{1} T_{1} R$ in the aorta and MA of the RT group were significantly increased compared with those of the control. (B) Protein expression levels of $\mathrm{AT}_{2} \mathrm{R}$ in the aorta and MA exhibited no significant difference between the RT and control groups. Values are presented as the mean \pm standard deviation ( $\mathrm{n}=6$ per group), ${ }^{*} \mathrm{P}<0.05$ vs. control. $\mathrm{AT}_{1} \mathrm{R}$, angiotensin II receptor type $1 ; \mathrm{AT}_{2} \mathrm{R}$, angiotensin II receptor type 2; MA, mesenteric arteries; RT, renal transplantation; Con, control.

$m R N A$ expression and protein levels of $C R E B-1$ and $E R-\alpha / \beta$ in blood vessels. To assess the association of transcription factor levels with $\mathrm{AT}_{1 \mathrm{a}} \mathrm{R}$ gene expression, CREB-1, ER- $\alpha$ and ER- $\beta$ mRNA and protein levels were evaluated in the blood vessels of the rats at 48 weeks after the transplantation surgery. The results of RT-qPCR and western blotting demonstrated that the mRNA and protein levels of CREB-1, ER- $\alpha$ and ER- $\beta$ in the aorta and mesenteric arteries did not differ significantly between the RT and control groups (Figs. 10 and 11).

\section{Discussion}

Elevated BP is one of the most common and serious complications following renal transplantation (30). In addition, epidemiological evidence suggests that the development of hypertension is an essential risk factor for morbidity and mortality following renal transplantation, and is also a prominent predictor for impaired graft survival independent of rejection episodes and transplant functions (5). According to current clinical recommendations, BP must be routinely measured during every outpatient visit following surgery (31). Although it is widely considered that the RAS serves definitive roles in 


\section{A}

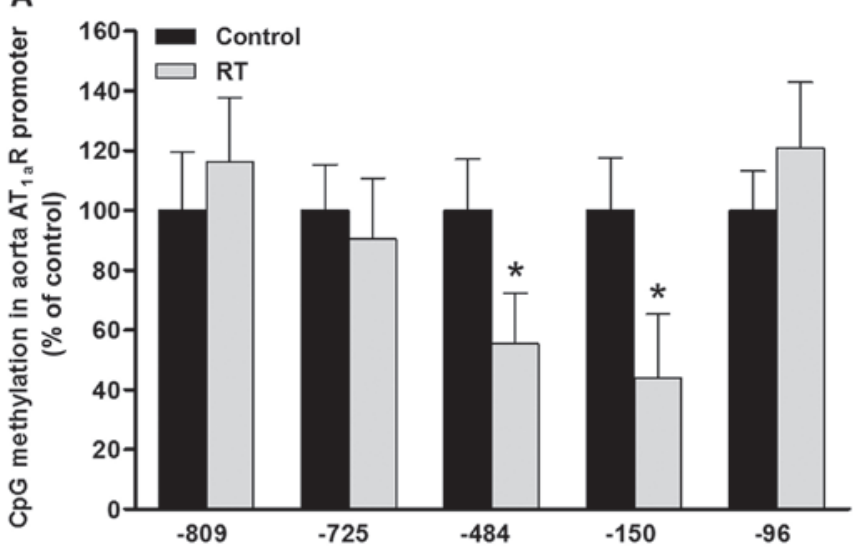

B

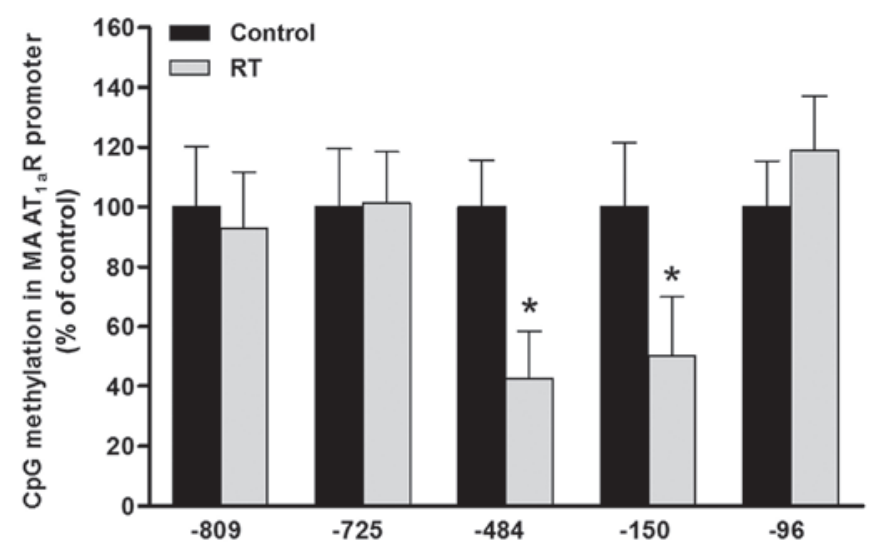

Figure 8. DNA methylation of $\mathrm{CpG}$ loci in the $\mathrm{AT}_{1 \mathrm{~g}} \mathrm{R}$ gene promoter in blood vessels at 48 weeks after transplantation surgery. In the (A) aorta and (B) MA, the levels of $\mathrm{CpG}$ methylation at ER- $\alpha / \beta$ (site -484) and CREB-1 (site -150) transcription factor binding sites in the promoter region of the $\mathrm{AT}_{1 \mathrm{a}} \mathrm{R}$ gene were significantly decreased in the RT group compared with the control; however, the levels of $\mathrm{CpG}$ methylation at the $-809,-725$ and -96 sites in the promoter region of the $\mathrm{AT}_{1 \mathrm{a}} \mathrm{R}$ gene exhibited no significant difference between the RT and control groups. Values are presented as the mean \pm standard deviation ( $\mathrm{n}=6$ per group), ${ }^{*} \mathrm{P}<0.05$ vs. control. $\mathrm{AT}_{1 \mathrm{a}} \mathrm{R}$, angiotensin II receptor type 1a; MA, mesenteric arteries; ER- $\alpha / \beta$, estrogen receptor- $\alpha / \beta$; CREB-1, cyclic AMP-responsive element-binding protein 1; RT, renal transplantation; Con, control.

the pathogenesis of primary hypertension, the cellular and molecular mechanisms underlying the progression of hypertension in response to the abnormal activation of RAS following renal transplantation have not been fully elucidated (32). Ang II-induced vascular contractility is indicated to be altered following renal transplantation (15). Accordingly, it is hypothesized that the altered expression of cardiovascular-responsive RAS-associated genes such as $\mathrm{AT}_{1} \mathrm{R}$ and $\mathrm{AT}_{2} \mathrm{R}$ in blood vessels influences the BP response to Ang II and increases the risk of hypertension following renal transplantation. In the present study, using the Fisher-Lewis rat renal transplantation model, a number of novel findings were observed for the recipient rat following renal transplantation: i) Ang II-induced BP response was prominently increased; ii) $\mathrm{AT}_{1} \mathrm{R}$-mediated vasoconstriction was increased in association with increased $\left[\mathrm{Ca}^{2+}\right]_{i}$; and iii) the mRNA and protein expression levels of vascular $\mathrm{AT}_{1} \mathrm{R}$ but not those of $\mathrm{AT}_{2} \mathrm{R}$, were significantly increased and were associated with epigenetic mechanisms such as DNA methylation.

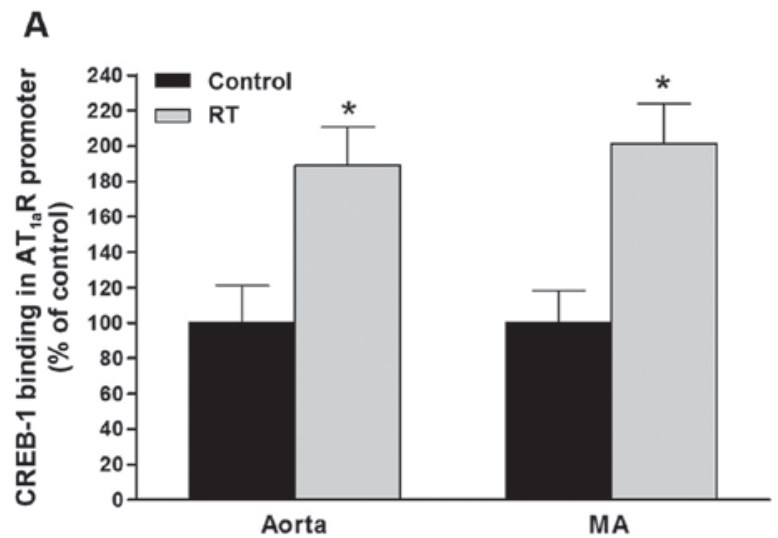

B
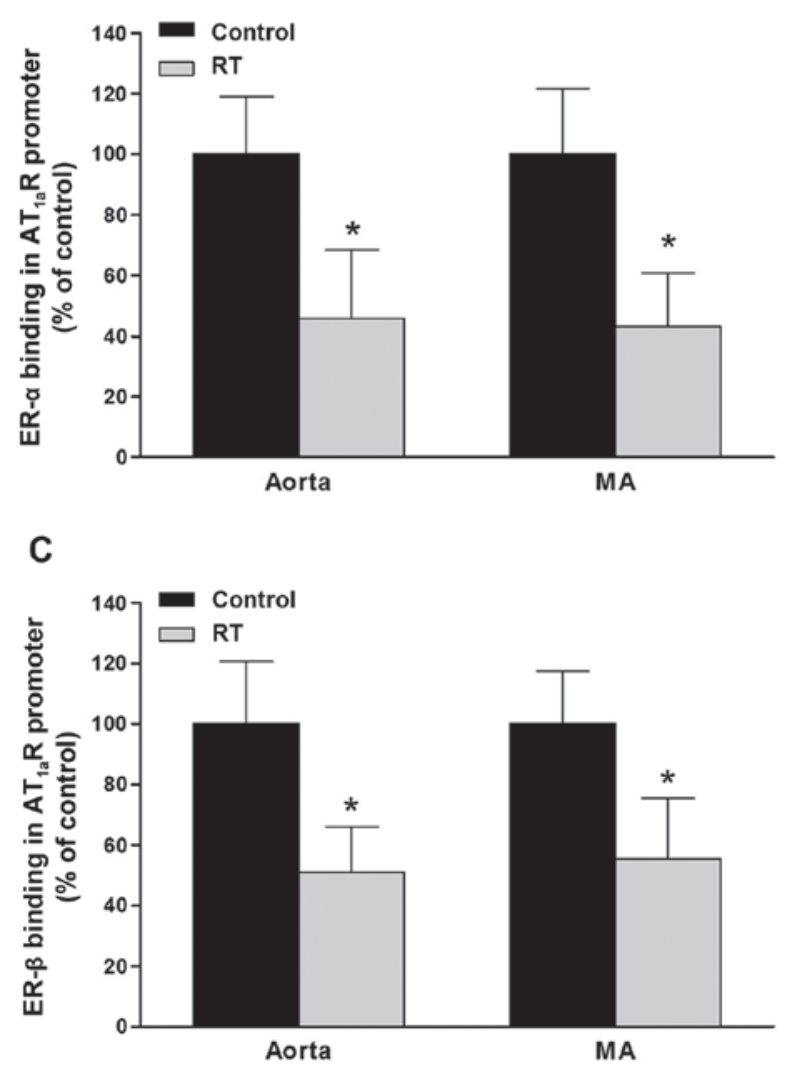

Figure 9. Binding capacity of CREB-1 and ER- $\alpha / \beta$ to the $\mathrm{AT}_{\mathrm{la}} \mathrm{R}$ gene promoter in blood vessels at 48 weeks after transplantation surgery. (A) The binding affinities of CREB-1 to the cAMP response element sequence in the $\mathrm{AT}_{1 \mathrm{a}} \mathrm{R}$ gene promoter of the aorta and MA the RT group were significantly increased compared with those of the control. The binding affinities of (B) ER- $\alpha$ and (C) ER- $\beta$ to the ER binding sequence in the $\mathrm{AT}_{1 \mathrm{a}} \mathrm{R}$ gene promoter of the aorta and MA in the RT group were significantly decreased compared with those in the control group. Values are presented as the mean \pm standard deviation ( $\mathrm{n}=6$ per group). ${ }^{*} \mathrm{P}<0.05$ vs. control. $\mathrm{AT}_{1 \mathrm{a}} \mathrm{R}$, angiotensin II receptor type 1a; MA, mesenteric arteries; ER- $\alpha / \beta$, estrogen receptor- $\alpha / \beta$; CREB-1, cyclic AMP-responsive element-binding protein 1; RT, renal transplantation; Con, control.

In the classic RAS system, Ang II is enzymatically generated in the circulation from angiotensinogen, which is produced and secreted by the liver (33). In general, Ang II mediates the majority of its effects via binding to $\mathrm{AT}_{1} \mathrm{R}$ and $\mathrm{AT}_{2} \mathrm{R}$ (12). These receptors are widely distributed in almost all organs and tissues (10). The regulation of cardiovascular homeostasis by Ang II is extensively controlled by the reactivity of $\mathrm{AT}_{1} \mathrm{R}$ and $\mathrm{AT}_{2} \mathrm{R}$ in the blood vessels, heart, kidney and brain (11). In particular, the 

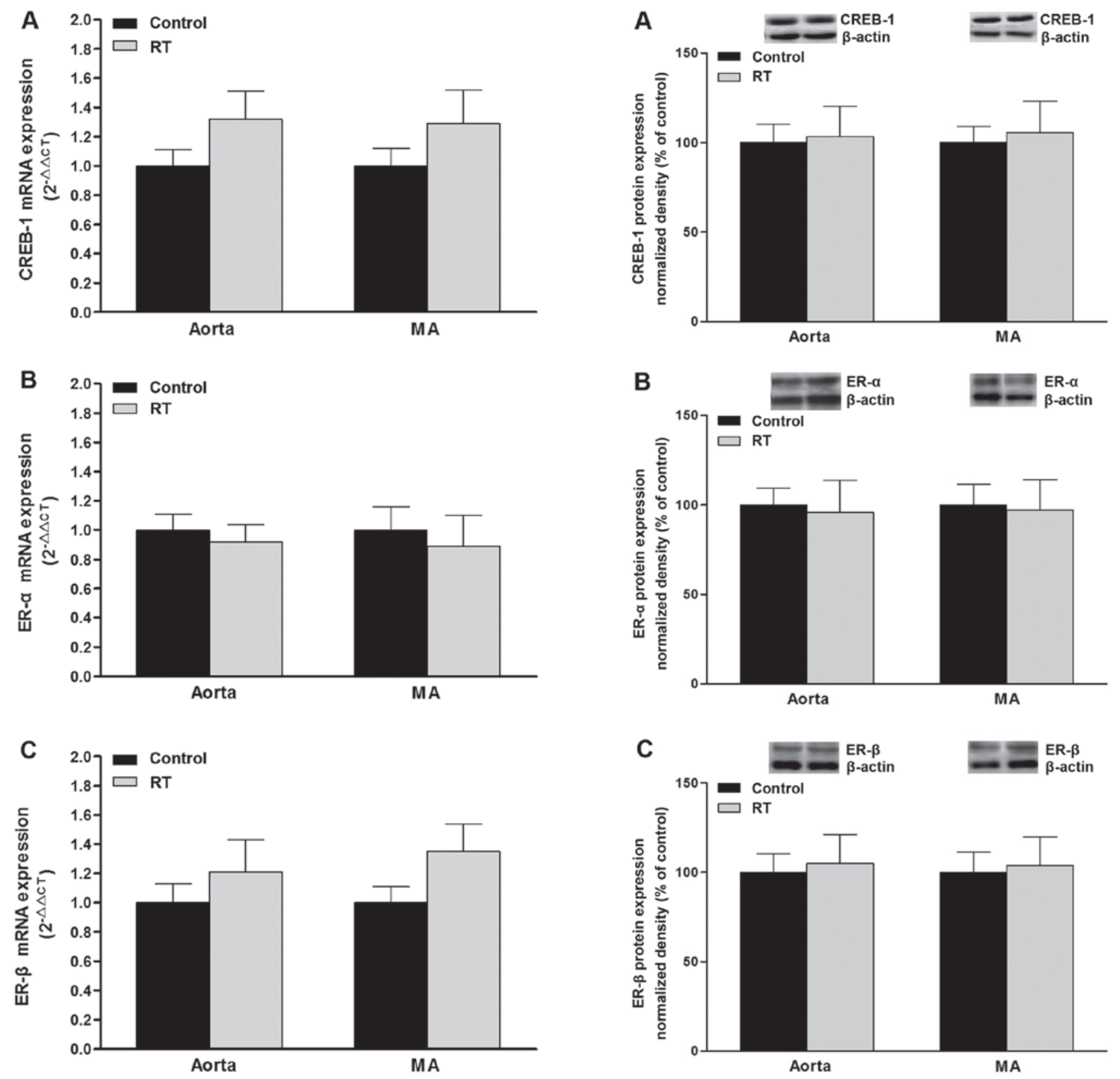

Figure 10. mRNA expression levels of CREB-1 and ER- $\alpha / \beta$ in blood vessels at 48 weeks after transplantation surgery. mRNA expression levels of (A) CREB-1, (B) ER- $\alpha$ and (C) ER- $\beta$ in the aorta and MA exhibited no significant differences between the RT and control groups. Values are presented as the mean \pm standard deviation ( $\mathrm{n}=6$ per group). MA, mesenteric arteries; ER- $\alpha / \beta$, estrogen receptor- $\alpha / \beta$; CREB- 1 , cyclic AMP-responsive elementbinding protein 1; RT, renal transplantation; Con, control.

Ang II-induced regulation of BP is largely mediated via $\mathrm{AT}_{1} \mathrm{R}$ and $\mathrm{AT}_{2} \mathrm{R}$ activation in blood vessels (10). In physiological conditions, by interacting with $\mathrm{AT}_{1} \mathrm{R}$ in the smooth muscle, Ang II is able to elicit the contraction of large and small-resistance blood vessels to maintain the vascular tone (12). However, in the pathogenesis of primary hypertension, by binding to either $\mathrm{AT}_{1} \mathrm{R}$ or $\mathrm{AT}_{2} \mathrm{R}$, Ang II may exert detrimental effects on vascular components, including smooth muscle cells, endothelial cells and fibroblasts, which may increase vasoconstriction and induce remodeling of the vascular structure (34). In the present study, the results revealed that the time-dependent elevation of arterial BP (SBP and DBP) induced by Ang II in the conscious

Figure 11. Protein expression levels of CREB-1 and ER- $\alpha / \beta$ in blood vessels at 48 weeks after transplantation surgery. Protein expression levels of (A) CREB-1, (B) ER- $\alpha$ and (C) ER- $\beta$ in the aorta and MA exhibited no significant differences between the RT and control groups. Values are presented as the mean \pm standard deviation ( $n=6$ per group). MA, mesenteric arteries; ER- $\alpha / \beta$, estrogen receptor- $\alpha / \beta$; CREB-1, cyclic AMP-responsive elementbinding protein 1; RT, renal transplantation; Con, control.

state was significantly increased in the RT group compared with the control group (Fig. 2). However, the basal arterial BP (SBP and DBP) exhibited no significant difference between the RT and control groups (Fig. 2). This indicates that a recipient would be more susceptible to the elevation of BP in response to Ang II following renal transplantation. Furthermore, following pretreatment with the selective $\mathrm{AT}_{1} \mathrm{R}$ antagonist losartan, the time-dependent elevation of arterial BP (SBP and DBP) induced by Ang II was largely attenuated, and exhibited no significant difference between the RT and control groups (Fig. 2). However, following pretreatment with the selective $\mathrm{AT}_{2} \mathrm{R}$ antagonist PD-123319, the time-dependent elevation of arterial BP (SBP 
and DBP) induced by Ang II was not markedly changed in the RT and control groups (Fig. 2). Thus, it is suggested that the enhanced Ang II-induced BP elevation detected in the recipient following renal transplantation is, at least in part, mediated by the increased cardiovascular response activated by $\mathrm{AT}_{1} \mathrm{R}$.

The local vascular RAS is critical in the regulation of vascular contractility and control of the arterial BP (10). From the morphological and physiological perspectives, arteries may be roughly categorized into large and small-resistance blood vessels, such as the aorta and mesenteric arteries, respectively (35). Clinical study indicates that, in the development and progression of hypertension, the increased vasoconstriction of the aorta and other large blood vessels should be tightly associated with abnormal increases in SBP; whereas, the abnormal reactivity of small-resistance blood vessels such as the mesenteric arteries should be largely correlated with an abnormal increase in DBP (36). In the present study, using aortic rings and mesenteric artery segments in vitro as large and small-resistance blood vessels, respectively, it was demonstrated that the Ang II-induced vascular contractility of large and small-resistance blood vessels was significantly increased in the RT group compared with the control group (Figs. 3 and 4). This result may, at least in part, explain why the arterial BP (SBP and DBP) elevation induced by Ang II was increased in the recipient following renal transplantation (Fig. 2). Furthermore, the selective $\mathrm{AT}_{1} \mathrm{R}$ antagonist (losartan) almost completely eradicated the Ang II-induced vasoconstriction of the aorta and mesenteric arteries, whereas the selective $\mathrm{AT}_{2} \mathrm{R}$ antagonist (PD-123319) had a minimal effect in the RT and control groups (Figs. 3 and 4). This may explain why the Ang II-induced arterial BP elevation in vivo was inhibited by losartan but not PD-123319 in the recipient following renal transplantation (Fig. 2). Accordingly, these results suggest that the increased BP elevation induced by Ang II in the recipient following renal transplantation is partly due to increased $\mathrm{AT}_{1} \mathrm{R}$-mediated vasoconstriction in large and small-resistance blood vessels.

Contraction and dilation of the vasculature are largely controlled by vascular smooth muscle cells and endothelial cells (37). Studies have revealed that the enhancement of endothelium-derived vasodilation may serve an important compensatory/protective role in preventing and ameliorating the development of hypertension (38). In the present study, to clearly observe the contraction of vascular smooth muscle, the Ang II-mediated vasoconstriction of the aorta and mesenteric arteries in the absence of endothelium was evaluated. In comparison with endothelium-intact vessels, Ang II-induced vasoconstriction in the aorta and mesenteric arteries was significantly increased in the absence of endothelium in the RT and control groups (Figs. 3 and 4). Additionally, in the absence of endothelium, Ang II-induced vasoconstriction in the aorta and mesenteric arteries was significantly increased in the RT group compared with the control (Figs. 3 and 4). Furthermore, without endothelium, as in the presence of endothelium, the Ang II-induced vasoconstriction was almost completely eradicated by losartan, but hardly altered by PD-123319 in the RT and control groups (Figs. 3 and 4). These results indicate the following transplantation, the $\mathrm{AT}_{1} \mathrm{R}$-mediated contraction of vascular smooth muscle is markedly increased in the large and small-resistance blood vessels of the recipient. Furthermore, the protective effects of endothelium-derived vasodilation may not be impaired but could have lost the ability to compensate for the over-activated vasoconstriction induced by Ang II following renal transplantation.

At the cellular and subcellular levels, the contraction of vascular smooth muscle mediated by $\mathrm{AT}_{1} \mathrm{R}$ activation involves complex downstream signaling (11). The increase of $\left[\mathrm{Ca}^{2+}\right]_{\mathrm{i}}$ is generally considered to serve as the fundamental determinant for vasoconstriction (39). In particular, following the interaction between Ang II and $\mathrm{AT}_{1} \mathrm{R}$, inositol trisphosphate (IP3) is generated from phosphatidylinositol-4,5-bisphosphate hydrolyzing when activated by phospholipase C. IP3 then stimulates the sarcoplasmic reticulum to mobilize intracellular $\mathrm{Ca}^{2+}$, leading to an increase in $\left[\mathrm{Ca}^{2+}\right]_{\mathrm{i}}(40)$. The production of diacylglycerol (DAG) is increased and protein kinase $\mathrm{C}$ is activated, which further promotes $\mathrm{Ca}^{2+}$ influx via certain ion channels (41). The increased $\left[\mathrm{Ca}^{2+}\right]_{\mathrm{i}}$ activates myosin light chain kinase and the phosphorylation of $20-\mathrm{kDa}$ myosin light chain $\left(\mathrm{MLC}_{20}\right)$, leading to the contraction of vascular smooth muscle cells (40). In the present study, due to the limitations of the IonOptix instrument system, simultaneous measurement of the vascular contractility and $\left[\mathrm{Ca}^{2+}\right]_{\mathrm{i}}$ was possible in the mesenteric arteries but not in the aorta. The results demonstrated that the Ang II-induced vasoconstriction and $\left[\mathrm{Ca}^{2+}\right]_{\mathrm{i}}$ were simultaneously increased in the mesenteric arteries in the RT group compared with the control (Fig. 5). Furthermore, the Ang II-induced increase in $\left[\mathrm{Ca}^{2+}\right]_{\mathrm{i}}$ was almost completely eliminated by losartan, but hardly altered by PD-123319 in the RT and control groups (Fig. 5). This suggests that the increased $\mathrm{AT}_{1} \mathrm{R}$-mediated vasoconstriction observed in the mesenteric arteries was closely associated with enhanced $\left[\mathrm{Ca}^{2+}\right]_{\mathrm{i}}$-dependent signaling in the vascular smooth muscle of the recipient following renal transplantation. However, it should be noted that, in addition to the aforementioned $\mathrm{Ca}^{2+}$ dependent mechanism, the inactivation of myosin light chain phosphatase and decreased dephosphorylation of $\mathrm{MLC}_{20}$ may in turn increase the sensitivity of $\mathrm{Ca}^{2+}$ at a fixed level of $\left[\mathrm{Ca}^{2+}\right]_{\mathrm{i}}$ to activate the contraction of vascular smooth muscle cells induced by Ang II (42). This $\mathrm{Ca}^{2+}$-independent mechanism is beyond the scope of the present study and requires investigation in future studies.

The RAS may be anatomically and functionally categorized into the systemic and local RAS, in the circulation and tissues, respectively (10). Furthermore, the abnormal activation of the local RAS may be predominant in the pathogenesis of hypertension (11). In the present study, the levels of Ang II in the RT group were significantly higher than those in the control group in both the aorta and mesenteric arteries (Fig. 1). These results, together with the aforementioned increased Ang II-induced vasoconstriction observed in vitro, suggest that the local vascular RAS was prominently over-activated in the recipient following renal transplantation. However, with regard to the circulation, the plasma concentration of Ang II in the RT group was significantly lower than that in the control (Fig. 1), which indicates that the systemic RAS was inhibited in the recipient following renal transplantation. Previous clinical and experimental studies have found that, in the early phase of hypertension, overactivation of the local RAS may provide negative feedback signals causing inhibition of the systemic RAS $(43,44)$. Thus, it is suggested in the recipient after renal transplantation, the inhibited systemic RAS serves a compensatory function that ameliorates the detrimental BP elevation induced by the abnormal activation of the local vascular RAS. 
This may explain why the basal BP was not observed to be elevated in the recipient following renal transplantation (Fig. 2). Typically, the production Ang II in the circulation and vascular tissue involves numerous enzymes, including renin and angiotensin-converting enzymes (45). Whether and to what extent these enzymes and functional products are affected by transplantation was beyond the scope of the present study and requires elucidation in the future.

Some uncertainty remains regarding the cellular and molecular mechanisms underlying the increased Ang II-induced vasoconstriction. There are at least two possible reasons for the changes of Ang II-induced contraction in vascular smooth muscle: i) $\mathrm{AT}_{1} \mathrm{R}$ and $\mathrm{AT}_{2} \mathrm{R}$ expression levels were changed; ii) the sensitivity and/or effects of the downstream signaling of $\mathrm{AT}_{1} \mathrm{R}$ and $\mathrm{AT}_{2} \mathrm{R}$ were altered in the vascular smooth muscle cells. In the present study, only the analysis of $A T_{1} R$ and $A T_{2} R$ expression levels in the blood vessels was conducted. The mRNA and protein expression levels of $\mathrm{AT}_{1} \mathrm{R}$ in the aorta and mesenteric arteries were significantly increased in the RT group compared with the control (Figs. 6 and 7), while those of $\mathrm{AT}_{2} \mathrm{R}$ exhibited no significant difference between the RT and control groups (Figs. 6 and 7), indicating that the effects of renal transplantation on vascular RAS are gene-specific. In rodents, there are two subtypes of the $A_{1} R$ gene, $A T_{1 a} R$ and $\mathrm{AT}_{1 \mathrm{~b}} \mathrm{R}$, which are located on different chromosomes (46). $\mathrm{AT}_{1 \mathrm{~b}} \mathrm{R}$ is mainly localized in the brain, for example, in the pituitary and adrenal glands, whereas $\mathrm{AT}_{1 \mathrm{a}} \mathrm{R}$ is widely dispersed in other organs and tissues, such as blood vessels (47). Thus, it is proposed that the elevated vascular levels of the $\mathrm{AT}_{1} \mathrm{R}$ gene in the recipient following renal transplantation was partly attributable to the increased transcriptional activity of the $\mathrm{AT}_{1 \mathrm{a}} \mathrm{R}$ gene in large and small-resistance blood vessels. Notably, changes of the transcriptional level of $\mathrm{AT}_{1} \mathrm{R}$ gene have been indicated to be epigenetically affected in the pathogenesis of hypertension, which may involve DNA methylation, post-translational histone modifications and non-coding RNAs (47). In particular, DNA methylation, occurring at the cytosine residues in $\mathrm{CpG}$ dinucleotide sequences, may alter the chromatin structure and the long-term transcriptional activity of the altered genes (48). Typically, the methylation modification of just one $\mathrm{CpG}$ dinucleotide can change the expression of the associated gene through affecting the binding affinity of certain transcription factors (49). Several $\mathrm{CpG}$ sites have been discovered in the sequence-specific transcription factor binding sequences in the $\mathrm{AT}_{1 \mathrm{a}} \mathrm{R}$ gene promoter region of rodents, including -809, -725, $-484,-150$ and $-96 \mathrm{CpG}$ loci (50). In the present study, MS-qPCR demonstrated that the DNA methylation levels of $\mathrm{CpG}$ sites in the -484 and -150 loci were significantly decreased in the aorta and mesenteric arteries of the RT group compared with the control (Fig. 8). Since the CpG loci of -484 and -150 correspond to ER and CREB transcription factor binding sequences, respectively, in the promoter region of the $\mathrm{AT}_{1 \mathrm{a}} \mathrm{R}$ gene, it is speculated that renal transplantation selectively decreased site-specific DNA methylation at the ER- and CREB-binding sequences and thereby alters the transcriptional efficacy of the vascular $\mathrm{AT}_{1 \mathrm{a}} \mathrm{R}$ gene in the recipient.

To investigate the effects of ER and CREB in the regulation of $\mathrm{AT}_{1 \mathrm{a}} \mathrm{R}$ gene transcriptional activity, ChIP assays were conducted to detect the interactions of ER- $\alpha / \beta$ and CREB- 1 with the respective gene-specific transcription factor binding sequences on promoter loci of the $\mathrm{AT}_{1 \mathrm{a}} \mathrm{R}$ gene in the intact chromatin. The binding affinity of CREB-1 to the cAMP response element in the promoter region of the vascular $\mathrm{AT}_{1 \mathrm{a}} \mathrm{R}$ gene was observed to be significantly increased in the aorta and mesenteric arteries of the RT group compared with the control (Fig. 9). Additionally, the expression of vascular CREB-1 (mRNA and protein) exhibited no significant difference between the RT and control groups (Figs. 10 and 11). CREB-1 is known to be an essential gene-specific factor for upregulating $\mathrm{AT}_{1 \mathrm{a}} \mathrm{R}$ gene transcription (51). It may be speculated that, due to the decreased DNA methylation level of the $-150 \mathrm{CpG}$ site, the binding capacity of CREB-1 to the vascular $\mathrm{AT}_{1 \mathrm{a}} \mathrm{R}$ gene promoter may be markedly increased, leading to an increase in the transcriptional activity of the $\mathrm{AT}_{1 \mathrm{a}} \mathrm{R}$ gene in the vasculature of the recipient following renal transplantation. Furthermore, the binding affinity of ER- $\alpha / \beta$ to the specific sequence in the promoter region of the $\mathrm{AT}_{1 \mathrm{a}} \mathrm{R}$ gene was significantly decreased in the aorta and mesenteric arteries of the RT group compared with the control (Fig. 9). In addition, the expression of vascular ER- $\alpha / \beta$ (mRNA and protein) exhibited no significant difference between the RT and control groups (Figs. 10 and 11). Previous studies have demonstrated that estrogen directly binds with ER to downregulate the transcriptional activity of the $\mathrm{AT}_{1 \mathrm{a}} \mathrm{R}$ gene in the vasculature, which prevents BP elevation in the pathogenesis of hypertension (52). It may be suggested that, due to the decreased DNA methylation level of the $-484 \mathrm{CpG}$ site, the binding capacity of ER to the promoter region of vascular $\mathrm{AT}_{1 \mathrm{a}} \mathrm{R}$ gene was markedly inhibited, so as to further increase the transcriptional activity of the vascular $\mathrm{AT}_{1 \mathrm{a}} \mathrm{R}$ gene in the recipient following renal transplantation. Clinical evidence confirms that estrogen exerts substantially protective roles that prevent the development of hypertension (53-55). The beneficial effects of estrogen in the reduction of vascular $\mathrm{AT}_{1 \mathrm{a}} \mathrm{R}$ gene expression may be impaired by DNA demethylation in the recipient following renal transplantation. However, why DNA demethylation at the -484 and -150 sites differentially affected the binding capacity of ER and CREB-1 to the promoter of the $\mathrm{AT}_{1 \mathrm{a}} \mathrm{R}$ gene is unknown and requires investigation.

In conclusion, the present study demonstrated that renal transplantation may cause Ang II-induced elevations of the BP to increase and abnormally activate the local vascular RAS, leading to the augmentation of $\mathrm{AT}_{1} \mathrm{R}$-mediated vasoconstriction associated with altered DNA methylation of the $\mathrm{AT}_{1 \mathrm{a}} \mathrm{R}$ gene in large and small-resistance blood vessels in the recipient. These results tentatively suggest that the susceptibility to hypertension is increased in the recipient following renal transplantation. Furthermore, epigenetic modifications such as DNA methylation of vascular $\mathrm{AT}_{1 \mathrm{a}} \mathrm{R}$ gene may be potential targets for preventing and treating hypertension.

\section{Acknowledgements}

The present study was supported by the Science and Technology Research Project of Heilongjiang Province Department of Education Project (grant no. 12531366).

\section{Competing interests}

The authors declare that they have no competing interests. 


\section{References}

1. Chandran S and Vincenti F: Clinical aspects: Focusing on key unique organ-specific issues of renal transplantation. Cold Spring Harb Perspect Med 4: 4, 2014

2. Lyerová L, Viklický O, Nemcová D and Teplan V: The incidence of infectious diseases after renal transplantation: A single-centre experience. Int J Antimicrob Agents 31 (Suppl 1): S58-S62, 2008

3. Saidi RF and Hejazii Kenari SK: Clinical transplantation and tolerance: Are we there yet? Int J Organ Transplant Med 5: $137-145,2014$

4. Holmberg $\mathrm{C}$ and Jalanko $\mathrm{H}$ : Long-term effects of paediatric kidney transplantation. Nat Rev Nephrol 12: 301-311, 2016.

5. Mitsnefes MM, Khoury PR and McEnery PT: Early posttransplantation hypertension and poor long-term renal allograft survival in pediatric patients. J Pediatr 143: 98-103, 2003.

6. Stoumpos S, Jardine AG and Mark PB: Cardiovascular morbidity and mortality after kidney transplantation. Transpl Int 28: 10-21, 2015.

7. Briese S, Claus M and Querfeld U: Arterial stiffness in children after renal transplantation. Pediatr Nephrol 23: 2241-2245, 2008

8. Cseprekál O, Kis E, Dégi AA, Kerti A, Szabó AJ and Reusz GS Bone metabolism and arterial stiffness after renal transplantation. Kidney Blood Press Res 39: 507-515, 2014.

9. Harrison-Bernard LM: The renal renin-angiotensin system. Adv Physiol Educ 33: 270-274, 2009.

10. Paul M, Poyan Mehr A and Kreutz R: Physiology of local reninangiotensin systems. Physiol Rev 86: 747-803, 2006.

11. Mehta PK and Griendling KK: Angiotensin II cell signaling: Physiological and pathological effects in the cardiovascular system. Am J Physiol Cell Physiol 292: C82-C97, 2007.

12. Karnik SS, Unal H, Kemp JR, Tirupula KC, Eguchi S Vanderheyden PM and Thomas WG: International Union of Basic and Clinical Pharmacology. XCIX. Angiotensin receptors: Interpreters of pathophysiological angiotensinergic stimuli [corrected]. Pharmacol Rev 67: 754-819, 2015.

13. de Gasparo M, Catt KJ, Inagami T, Wright JW and Unger T: International union of pharmacology. XXIII. The angiotensin II receptors. Pharmacol Rev 52: 415-472, 2000

14. van Thiel BS, van der Pluijm I, te Riet L, Essers J and Danser AH: The renin-angiotensin system and its involvement in vascular disease. Eur J Pharmacol 763: 3-14, 2015.

15. Gabriëls G, August C, Grisk O, Steinmetz M, Kosch M, Rahn KH and Schlatter E: Impact of renal transplantation on small vessel reactivity. Transplantation 75: 689-697, 2003.

16. Formica RN Jr, Friedman AL, Lorber MI, Smith JD, Eisen T and Bia MJ: A randomized trial comparing losartan with amlodipine as initial therapy for hypertension in the early post-transplant period. Nephrol Dial Transplant 21: 1389-1394, 2006.

17. Pilmore HL, Skeans MA, Snyder JJ, Israni AK and Kasiske BL: Cardiovascular disease medications after renal transplantation: Results from the patient outcomes in renal transplantation study. Transplantation 91: 542-551, 2011.

18. Goldberg AD, Allis CD and Bernstein E: Epigenetics: A landscape takes shape. Cell 128: 635-638, 2007.

19. Zoghbi HY and Beaudet AL: Epigenetics and human disease Cold Spring Harb Perspect Biol 8: a019497, 2016.

20. Mas VR, Le TH and Maluf DG: Epigenetics in kidney transplantation: Current evidence, predictions, and future research directions. Transplantation 100: 23-38, 2016.

21. Bontha SV, Maluf DG, Mueller TF and Mas VR: Systems biology in kidney transplantation: The application of multi-omics to a complex model. Am J Transplant 17: 11-21, 2017.

22. Kim JI, Jung KJ, Jang HS and Park KM: Gender-specific role of HDAC11 in kidney ischemia- and reperfusion-induced PAI-1 expression and injury. Am J Physiol Renal Physiol 305: F61-F70, 2013.

23. Sui W, Lin H, Peng W, Huang Y, Chen J, Zhang Y and Dai Y: Molecular dysfunctions in acute rejection after renal transplantation revealed by integrated analysis of transcription factor, microRNA and long noncoding RNA. Genomics 102: 310-322, 2013.

24. Betts G, Shankar S, Sherston S, Friend P and Wood KJ: Examination of serum miRNA levels in kidney transplant recipients with acute rejection. Transplantation 97: e28-e30, 2014

25. Becker-Cohen R, Nir A, Rinat C, Feinstein S, Algur N, Farber B and Frishberg Y: Risk factors for cardiovascular disease in children and young adults after renal transplantation. Clin J Am Soc Nephrol 1: 1284-1292, 2006.

26. Baumann M, Chang J, Thürmel K, Roos M, von Eynatten M, Sollinger D, Lutz J and Heemann U: Fisher-Lewis kidney transplantation model as a tool for investigation of transplantationinduced cardiomyopathy. Transplant Proc 41: 2612-2615, 2009.

27. Xiao D, Xu Z, Huang X, Longo LD, Yang S and Zhang L: Prenatal gender-related nicotine exposure increases blood pressure response to angiotensin II in adult offspring. Hypertension 51: 1239-1247, 2008.
28. Livak KJ and Schmittgen TD: Analysis of relative gene expression data using real-time quantitative PCR and the 2(-Delta Delta C(T)) Method. Methods 25: 402-408, 2001.

29. Gasc JM, Shanmugam S, Sibony M and Corvol P: Tissue-specific expression of type 1 angiotensin II receptor subtypes. An in situ hybridization study. Hypertension 24: 531-537, 1994.

30. Bulum B, Ozcakar ZB, Kavaz A, Tutar E, Ekim M and Yalcinkaya F: Hypertension in children after renal transplantation. Pediatr Int 57 1138-1142, 2015.

31. Weir MR, Burgess ED, Cooper JE, Fenves AZ, Goldsmith D, McKay D, Mehrotra A, Mitsnefes MM, Sica DA and Taler SJ: Assessment and management of hypertension in transplant patients. J Am Soc Nephrol 26: 1248-1260, 2015

32. Chatzikyrkou C, Eichler J, Karch A, Clajus C, Scurt FG, Ramackers W, Lehner F, Menne J, Haller H, Mertens PR, et al: Short- and long-term effects of the use of RAAS blockers immediately after renal transplantation. Blood Press 26: 30-38, 2017.

33. Reudelhuber TL: The renin-angiotensin system: Peptides and enzymes beyond angiotensin II. Curr Opin Nephrol Hypertens 14: 155-159, 2005.

34. Steckelings UM, Rompe F, Kaschina E and Unger T: The evolving story of the RAAS in hypertension, diabetes and CV disease: Moving from macrovascular to microvascular targets. Fundam Clin Pharmacol 23: 693-703, 2009.

35. Rizzoni D, De Ciuceis C, Salvetti M, Paini A, Rossini C, Agabiti-Rosei $\mathrm{C}$ and Muiesan ML: Interactions between macroand micro-circulation: Are they relevant? High Blood Press Cardiovasc Prev 22: 119-128, 2015

36. Kaplan NM and VictorRG(eds): Primary hypertension: Pathogenesis (with a special section on renal denervation and carotid barorecptor pacing). In: Kaplan's Clinical Hypertension. 11th edition. Williams and Wilkins, Philadelphia, PA, pp40-115, 2014.

37. Triggle CR, Samuel SM, Ravishankar S, Marei I, Arunachalam G and Ding H: The endothelium: Influencing vascular smooth muscle in many ways. Can J Physiol Pharmacol 90: 713-738, 2012.

38. Kang KT: Endothelium-derived relaxing factors of small resistance arteries in hypertension. Toxicol Res 30: 141-148, 2014.

39. Touyz RM and Schiffrin EL: Signal transduction mechanisms mediating the physiological and pathophysiological actions of angiotensin II in vascular smooth muscle cells. Pharmacol Rev 52: 639-672, 2000

40. Horowitz A, Menice CB, Laporte R and Morgan KG: Mechanisms of smooth muscle contraction. Physiol Rev 76: 967-1003, 1996.

41. Perez-Vizcaino F, Cogolludo A and Moreno L: Reactive oxygen species signaling in pulmonary vascular smooth muscle. Respir Physiol Neurobiol 174: 212-220, 2010.

42. Hansen PB: The complex field of interplay between vasoactive agents. Kidney Int 76: 929-931, 2009.

43. Beevers DG, Morton JJ, Nelson CS, Padfield PL, Titterington M and Tree M: Angiotensin II in essential hypertension. Br Med J 1: 415, 1977.

44. Morton JJ, Garcia del Rio C and Hughes MJ: Effect of acute vasopressin infusion on blood pressure and plasma angiotensin II in normotensive and DOCA-salt hypertensive rats. Clin Sci (Lond) 62: 143-149, 1982

45. Campbell DJ: Angiotensin II generation in vivo: Does it involve enzymes other than renin and angiotensin-converting enzyme? J Renin Angiotensin Aldosterone Syst 13: 314-316, 2012.

46. Kakar SS, Sellers JC, Devor DC, Musgrove LC and Neill JD: Angiotensin II type-1 receptor subtype cDNAs: Differential tissue expression and hormonal regulation. Biochem Biophys Res Commun 183: 1090-1096, 1992.

47. Millis RM: Epigenetics and hypertension. Curr Hypertens Rep 13: 21-28, 2011.

48. Deaton AM and Bird A: $\mathrm{CpG}$ islands and the regulation of transcription. Genes Dev 25: 1010-1022, 2011.

49. Jones PA: Functions of DNA methylation: Islands, start sites, gene bodies and beyond. Nat Rev Genet 13: 484-492, 2012.

50. Xiao D, Dasgupta C, Li Y, Huang X and Zhang L: Perinatal nicotine exposure increases angiotensin II receptor-mediated vascular contractility in adult offspring. PLoS One 9: e108161, 2014.

51. Haack KK, Mitra AK and Zucker IH: NF- $\kappa$ B and CREB are required for angiotensin II type 1 receptor upregulation in neurons. PLoS One 8: e78695, 2013.

52. Nickenig G, Strehlow K, Wassmann S, Bäumer AT, Albory K, Sauer $\mathrm{H}$ and Böhm M: Differential effects of estrogen and progesterone on AT(1) receptor gene expression in vascular smooth muscle cells. Circulation 102: 1828-1833, 2000.

53. Wenger NK, Speroff L and Packard B: Cardiovascular health and disease in women. N Engl J Med 329: 247-256, 1993.

54. Miller VM and Duckles SP: Vascular actions of estrogens: Functional implications. Pharmacol Rev 60: 210-241, 2008.

55. El-Mas MM and Abdel-Rahman AA: Longitudinal assessment of the effects of oestrogen on blood pressure and cardiovascular autonomic activity in female rats. Clin Exp Pharmacol Physiol 36: 1002-1009, 2009. 